\title{
Design Consideration for Additive Manufacturing: Fused Deposition Modelling
}

\author{
Ala'aldin Alafaghani, Ala Qattawi*, Muhammad Ali Ablat \\ Department of Mechanical Engineering, University of California, Merced, USA \\ Email: aalafaghani@ucmerced.edu, aqattaawi@ucmerced.edu, ^amaimaitiaili@ucmerced.edu
}

How to cite this paper: Alafaghani, A., Qattawi, A. and Ablat, M.A. (2017) Design Consideration for Additive Manufacturing: Fused Deposition Modelling. Open Journal of Applied Sciences, 7, 291-318. https://doi.org/10.4236/ojapps.2017.76024

Received: May 15, 2017

Accepted: June 26, 2017

Published: June 29, 2017

Copyright ( $) 2017$ by authors and Scientific Research Publishing Inc. This work is licensed under the Creative Commons Attribution International License (CC BY 4.0).

http://creativecommons.org/licenses/by/4.0/ c) (i) Open Access

\begin{abstract}
Additive Manufacturing (AM) technologies have progressed in the past few years and many of them are now capable of producing functional parts instead of mere prototypes. AM provides a multitude of benefits, especially in design freedom. However, it still lacks industrial relevance because of the absence of comprehensive design rules for AM. Although AM is usually advertised as being the solution for all traditional manufacturing design limitations, the fact is that AM only replaces these limitations with a different set of restrictions. To fully exploit the advantages of AM, it is necessary to understand these limitations and consider them early during the design process. The establishment of design considerations in AM enables parts and process optimization. This paper discusses the design considerations that will lead to optimize part quality. Specifically, the work discusses the Fused Deposition Modeling (FDM) due to its common use and availability. These considerations are drawn from literature and from experiments done by the authors. The experiments done by the authors include an investigation for the influence of elevated service temperature on the performance of FDM PLA parts, benchmarking the capability of FDM to print overhangs and bridges without supports, studying the influence of processing parameters over dimensional accuracy, and the effect of processing parameters on the final FDM samples modulus of elasticity. The work presents a case study investigating the correct clearances for FDM parts and finally a redesign for AM case study of a support bracket originally manufactured using traditional manufacturing methods taking into consideration the design considerations discussed in this paper.
\end{abstract}

\section{Keywords}

Fused Deposition Modeling, Design for Manufacturing, Design for Additive Manufacturing, 3D Printing 


\section{Introduction}

Fused Deposition Modelling (FDM) is an Additive Manufacturing (AM) technology that builds parts by heating and extruding filaments through a small nozzle. FDM usually deals with thermoplastics or composite materials. The nozzle follows computer controlled paths as in Computer Numerical Control machines (CNCs) while extruding the material to draw layers on top of each other to create the part as shown in Figure 1. The FDM process belongs to the 3D printing prototyping processes.

FDM was developed in the 1980s and commercialized in 1990 as a rapid prototyping technology. FDM computer programs perform slicing and patching of the part's cross section to create a sequence of extruded layers. These extruded layers are formed from contour raster or occasionally called shells. Shells are filled with infill raster as shown in Figure 2(a). Typically, the tool path prepared by the slicing program starts by fusing the contours that outline the layers. Depending on the slicing software, the number of the contours can be specified either by inputting the number of contours or the thickness of the shell and then the number of contours will be automatically calculated by defining the thickness of the contours.

After printing the outlines, the extruder fills the area inside the contours with infill patterns. Common infill patterns include honey comb, triangular and rectilinear infill patterns as shown in Figure 2(b). In most available software, the user can define the gap between each raster, which is called the overlap when the

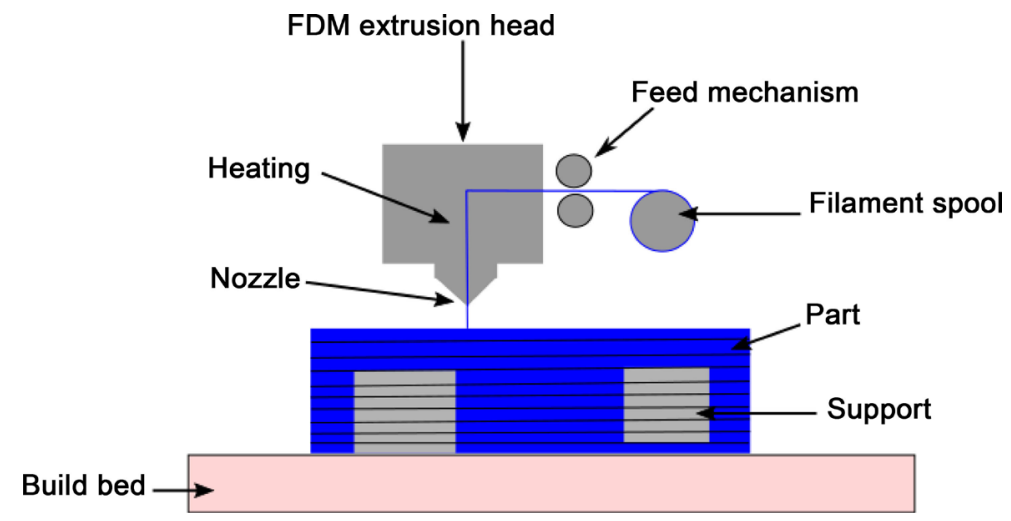

Figure 1. FDM schematic showing basic components.

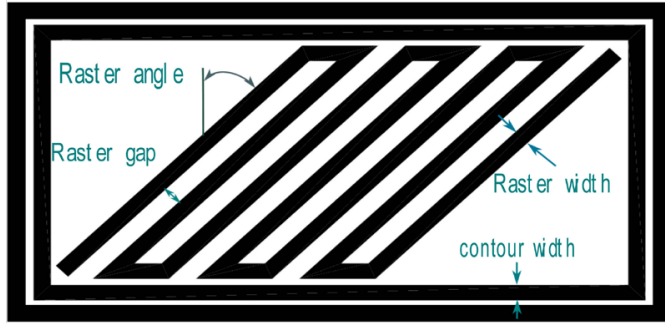

(a)

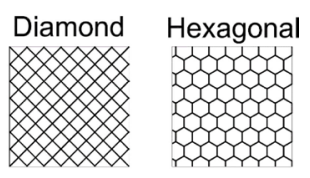

(b)

Figure 2. Schematic of a layer showing main processing parameters: (a) Showing the parameters of a layer; (b) Showing common layer infill patterns. 
gap is negative. The generated design can interact with Computer-Aided Design (CAD) tools via an STL file type.

FDM technology is being commercialized as a rapid manufacturing technology as other AM schemes and advertised with "your imagination is the limit". The fact is, at least currently, most AM technologies only replace the limitations of traditional manufacturing methods with new restrictions and challenges. According to Wittbrodt et al. [1], the FDM technology can be implemented feasibly even on a house hold level.

Despite the potential of FDM process in adding flexibility and reducing shape dedicated tools requirements, the current body-of-knowledge is lacking the design considerations necessary for a designer to guide the design of the part to meet the fabrication process requirements. A scheme is known as Design-for Manufacturing (DFM) [2] [3] [4] [5] [6], where the design of a part is modified to meet the process requirements of the selected fabrication process as early as the initial design phase.

Many researchers investigated the effect of FDM process parameters on the properties of the final part [7] [8] and available literature discusses improvements to the FDM process such as tool layering path [9] and deposition process analysis [10] [11]. While other researchers focused on the integration of the AM process into the industrial or the education scheme [12].

However, the body-of knowledge lack comprehensive analysis for the design guidelines for parts fabricated by FDM in terms of the process parameter. This paper research goal is to answer the following questions:

1) What are the FDM process parameters that affect the final parts characteristics?

2) What are the FDM design guidelines necessary to apply DFM principles during initial stages of the part's design?

3) Finally, a case study is presented to demonstrate the effect of FDM on the final part design.

This paper discusses the major design considerations for FDM parts from manufacturing/fabrication and functionality point of views. The design consideration investigated in this work will focus on the mechanical properties and topology of FDM parts. Other aspects such as thermal or electrical properties are out of the scope of this paper.

\section{Design Considerations}

FDM parts start with an idea or identification of a need and coming up with a function to aid that need or improve an existing system. Regularly, it is not feasible to request a new design for every updated need. Therefore, experience and use of existing designs are employed to reduce design cost and time. However, available earlier designs are set to be fabricated by other manufacturing methods, which are not necessarily compatible with FDM. In the case of FDM, there are sets of limitations that need to be taken into consideration, such as the part's orientation, functional optimization and manufacturing, paths optimization [13] and the 
multiple processing parameters that can affect the resulted part's properties.

The following section investigates the FDM processing parameters and their optimized values that can be set during the initial phases of the part's design.

\subsection{CAD Software and CAE}

CAD tools are necessary to successfully utilize AM technologies. CAD tools were optimized to aid the requirements and limitations of traditional manufacturing methods. Most CAD tools are built with the assumption of homogenous part's interior from both geometrical and materials point of views. An appropriate CAD tool for AM should allow the freedom to tailor the material's distribution and composition inside the part. In addition, it should allow the part's fabrication to be free of the constraints of traditional manufacturing methods. Thus, we optimize the topology of the part according to the loads and functionality instead of manufacturability. An example of used CAD tools was discussed in Srinivas Bhashyam et al. 2000 [14] and David W. Rosen 2007 [15], where various approaches were suggested to build heterogeneous parts. Currently, there are some commercial CAD tools that support AM such as Creo $4.0^{\circledR}$ Additive Manufacturing, which allows the fabrication of the parts and its interior parametrically and slice it for printing directly. Solid Thinking ${ }^{\circledR}$ is an example of CAD software that allows topology optimization as per the loading and the user defined requirements.

Due to the nature of AM that builds the parts layer by layer, the mechanical properties of the part are a function of the material used and the processing parameters. Processing parameters include the building orientation, extrusion temperature, overlap percentage, infill patterns and many others. Therefore, the strength of the part and its stiffness depend on the strength of the fusion and bonding between the extruded infill and the air gaps separating them. This makes simulating FDM parts in FEA a challenging task. Until now, there are no available packages for simulating AM parts and research is still in progress. In literature, there are several approaches taken in simulating AM parts. The first approach is done by testing tensile specimens in all principle directions to collect the stiffness matrix of the material. Then using this stiffness matrix simulations can be performed and verified [16]. However, this method does not show stress concentrations or explain the failure patterns. In [17], the FDM parts were simulated by adding air gaps according to their relative density to the raw filament. The gaps were made to represent the shape of the infill patterns. This explains the stress concentrations and the failure criteria. However, the part was still considered to be a continuum density instead of layers. In [18], the simulation model was built by patterning cylinders between 400 - 2000 times to create the specimen's gauge length. This method should represent the nature of FDM parts. However, it requires great computational power to simulate complex parts.

\subsection{Material}

The material library for FDM is constantly increasing to improve the applicabil- 
ity of FDM [19] [20]. However, the available materials are usually limited to thermoplastics, composites with thermoplastic. That is because most commercial FDM extruders are limited to up to $300^{\circ} \mathrm{C}$ while enabling rapid solidification so that the printed layers do not lose shape. There are some materials that have high glass transition temperatures such as PEEK. However, PEEK requires extrusion temperature above $300^{\circ} \mathrm{C}$, which most commercial FDM systems cannot produce except after modifying the extrusion head and replacing the thermoset with a thermocouple.

Consequently, when designing for FDM, designers are limited by the small range of materials. Currently, the most common FDM filaments are PLA, ABS and Nylon for printing parts while PVA and HIPS are the most common support filaments due to their dissolvability. New filaments that use TPE or TPU (Thermoplastic polyurethane) print parts with much higher elasticity than ABS and PLA. Composite filaments include carbon fiber, metal powder or wood fibers with PLA, Nylon [21] or ABS [22]. Among the most common three filaments, Nylon has the highest strength and flexibility, followed with PLA that has a medium strength and least flexibility [23]. Finally, ABS has the lowest strength accompanied with higher flexibility than PLA. ABS has the advantage of being dissolvable in acetone [24], which gives the ability to chemically treat its surface for better finishing. Table 1 lists the conservative mechanical properties of the most common filaments. Because of the low melting and glass transition temperatures, most FDM commercial filaments are not suitable for high temperature applications above $200^{\circ} \mathrm{C}$.

The mechanical properties of the material degrade significantly near the glass transition temperatures as shown in an experiment conducted by the authors. The tensile test specimens of PLA material were created in both orientations; horizontally and vertically and tested at room temperature, $50^{\circ} \mathrm{C}$ and $60^{\circ} \mathrm{C}$ using a controlled oven chamber attached to the universal tensile testing machine. A total of 18 fabricated specimens were tested in addition to 9 filament (raw material) specimens. The FDM specimens were fused using $0.20 \mathrm{~mm}$ layer thickness, three shells, $0.50 \mathrm{~mm}$ raster width, an extrusion temperature of $200^{\circ} \mathrm{C}$, and 40 $\mathrm{mm} / \mathrm{s}$ printing speed with a nozzle of $0.5 \mathrm{~mm}$ in diameter on Taz $6^{\circledR} \mathrm{FDM}$ system using Pro series PLA filament of $3.0 \mathrm{~mm}$ diameter. Figure 3 illustrates the dimensions of the fabricated samples. Although the specimens showed comparable properties at room temperature, at temperatures close to the glass transition, the mechanical properties dropped drastically as shown in Figure 4.

Table 1. Conservative mechanical properties of FDM printed parts.

\begin{tabular}{cccccc}
\hline Material & $\begin{array}{c}\text { Flexural } \\
\text { Modulus } \\
{[\mathrm{MPa}]}\end{array}$ & $\begin{array}{c}\text { Young's } \\
\text { Modulus } \\
{[\mathrm{MPa}]}\end{array}$ & $\begin{array}{c}\text { Flexural } \\
\text { Strength } \\
{[\mathrm{MPa}]}\end{array}$ & $\begin{array}{c}\text { Ultimate } \\
\text { Strength } \\
{[\mathrm{MPa}]}\end{array}$ & $\begin{array}{c}\text { Ductility } \\
{[\mathrm{mm} / \mathrm{mm}]}\end{array}$ \\
\hline ABS [7] [45] [59] & 1250 & 1600 & 40 & 25 & $5 \%$ \\
PLA [60] & - & 3333 & - & 50 & $1.5 \%$ \\
Nylon [61] & 1200 & 1400 & 60 & 50 & $5 \%$ \\
\hline
\end{tabular}




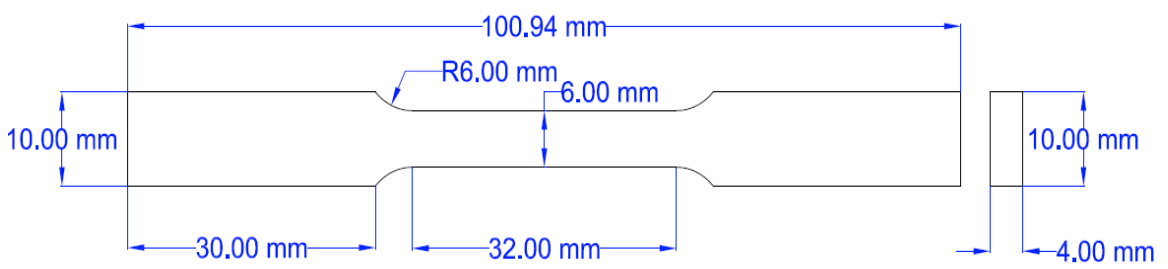

Figure 3. The dimensions of the tensile test specimens. Samples are tested at different environmental temperatures using a controlled oven chamber attached to the universal tensile testing machine.

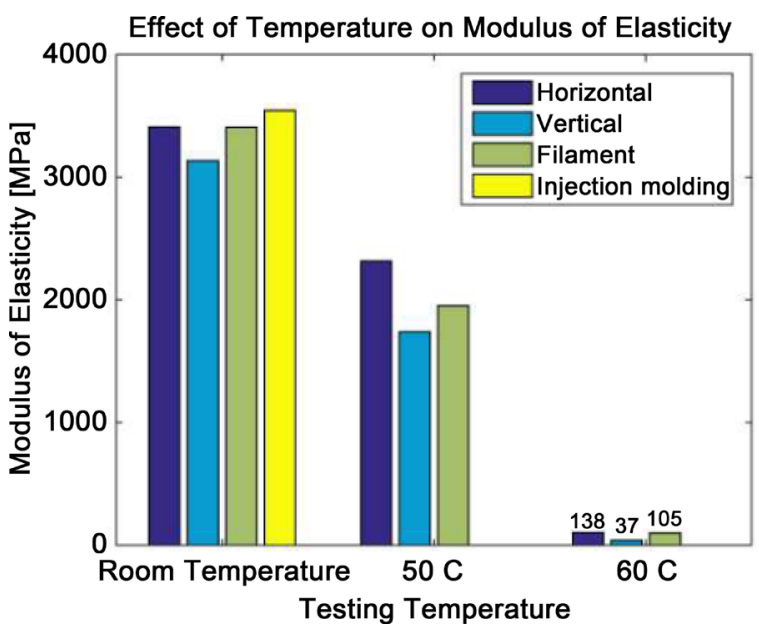

Figure 4. Modulus of elasticity of FDM PLA samples at various temperatures highlighting the degradation of the mechanical properties at temperatures close to glass transition temperature of PLA.

Figure 4 indicates the results for four cases, those are the samples fabricated horizontally relative to the loading direction, samples fabricated vertically relative to the loading direction, raw material filament, and the typical injection molding PLA. The modules of elasticity results show a significant reduction at $50^{\circ} \mathrm{C}$ environmental temperature compared to room temperature. It is also noted that the injection molding PLA has a higher modulus of elasticity at room temperature than the rest three cases. In addition, at $60^{\circ} \mathrm{C}$ the modulus of elastic for the AM PLA samples reduced to a negligible value compared to the room temperature and the $50^{\circ} \mathrm{C}$ samples since $60^{\circ} \mathrm{C}$ is very close to the glass transition temperature of PLA. We can see that FDM parts maintained their anisotropy even at elevated temperatures where parts fabricated horizontally with their layers parallel to the load show comparable stiffness and strength to the raw filament. On the other hand, vertically fabricated parts with their layers normal the load exhibit significantly lower stiffness. Finally, the injection modeling PLA exhibited slightly higher modules of elasticity than any FDM sample at room temperature.

\subsection{Size and Dimensions}

One of the major current limitations of FDM, and AM in general, is the small build volume that the process permits. Though there are FDM printers with 
CARTESIAN

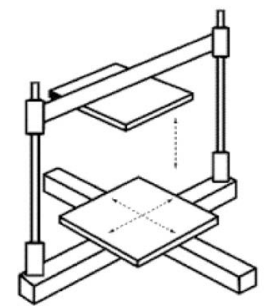

DELTA

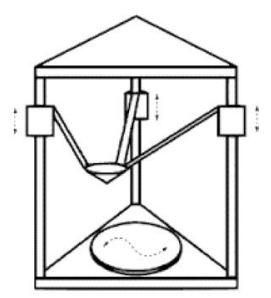

Figure 5. Schematic showing Cartesian and Delta axes available in FDM 3D printers [25].

larger building volumes, most commercial FDM printers have building volumes less than $30 \mathrm{~cm} \times 30 \mathrm{~cm} \times 30 \mathrm{~cm}$. Similarly, most FDM printers have Cartesian coordinate axis. However, many FDM printers have Delta coordinate as shown in Figure 5. This main difference is in the distribution of the building volume. Typically, the Cartesian FDM printers have bigger building bed but smaller building dimension in the height direction, while Delta FDM printers have smaller bed area in comparison to their Z-axis or height. The distribution of the building volume is important as it can limit the possible orientations for a given part. In addition, one advantage of AM is to avoid unnecessary assemblies by printing components as one part allowing for components consolidation. However, the limited building volume might force portioning the design into smaller parts. Consequently, adding assembly steps to the manufacturing process. For materials prone to distortion and warpage, the utilization of the full bed might result with parts of poor quality due to the temperature variations along the edges of the heated bed and different cooling rate, especially in an open FDM system [26].

\subsection{Topology}

Most FDM printers have its manufacturer nozzle positioning accuracy procedure. Typical values range between $10-12.5$ microns for the XY plane and 1 2.5 microns in the $\mathrm{Z}$ direction [27] [28]. Some equipment has even smaller values [29]. This accuracy might not reflect exactly on the resolution of the resulted FDM parts since more factors affect the parts' resolution; such as the nozzle diameter and the filament material properties combined with the processing parameters used. Typical nozzle diameters range between $0.30-1.00 \mathrm{~mm}$ with 0.40 and $0.50 \mathrm{~mm}$ nozzles being the most common.

Accordingly, designers should be aware of small details in their designs such as angles, fillets, curves, small holes, and thin walls, as they might not be fabricated as intended in the design. Childs and Juster [30] investigated the dimensional accuracy of many AM technologies and tested how well small features such as short linear shapes, thin walls and small holes can be produced using FDM. It was found that FDM was not able to fuse holes with diameter of $1 \mathrm{~mm}$ or thin walls of $0.5 \mathrm{~mm}$. In Johnson et al. [31], a benchmarking part was printed with small features such as holes, cylinders, and notches with dimensions no smaller than $1 \mathrm{~mm}$. It was found that for small cylinders with $6 \mathrm{~mm}$ diameter the 
deviation was $0.26 \mathrm{~mm}$ while for the notch with $2 \mathrm{~mm}$ the deviation was 0.35 $\mathrm{mm}$.

In conclusion, features with smaller dimension than $1 \mathrm{~mm}$ should be avoided as they might fail to be rendered. Features between $1 \mathrm{~mm}$ and $5 \mathrm{~mm}$ will have deviations between $0.15 \mathrm{~mm}-0.35 \mathrm{~mm}$. In addition, it is favorable to have thin walls with thicknesses equal to an integer multiplication of the nozzle diameter or raster width [32]. Larger value of raster width will build a part with a stronger interior. Smaller value will require less production time and material. The value of raster width is mainly a function of the nozzle diameter.

Overhangs features, shown in Figure 6(a), are a main aspect in FDM that designers should carefully consider during the conceptual phase of CAD model. In general, there is a limit to the length of unsupported depositions that can be printed using FDM [5]. In the work of Belter and Dollar [33], 30 over-hanged features with length of $3 \mathrm{~mm}$ were successful printed with no support. In Johnson et al. [31] work, longer overhangs were successfully printed without support as well. However, the overhangs features were fabricated with deviated angles. For example, the overhang features with an angle of $15^{\circ}$ can be fabricated with an angle of $15.5^{\circ}$. Typically, any section of the part that extends out at a $45^{\circ}$ angle is printed with supports underneath to avoid warpage and collapsing during deposition. Currently, available open source or commercial slicing software can generate these supports automatically. In [5] many design rules for features joining or separating along the printing direction were given.

This limitation is important due to the disadvantages of adding supports such as extending the printing time and wasting raw filament.

In some cases, the overhanging parts are unavoidable and require necessary supports. The supports can be located in inaccessible regions and cannot be removed at the end. Such supports are fused using different material filaments that are usually water soluble which works if the solvent has access to the support. However, not all FDM printers have the capability to print using two extruders so that it can build the supports using different materials than the main part. Because of these disadvantages, it is important to know the limits of FDM printer to fabricate overhangs and bridges without supports.

As shown in Figure 6(b) an overhang part was printed to test the limits to print overhangs inclined with different angles. Using $0.20 \mathrm{~mm}$ layer thickness, three shells, $0.50 \mathrm{~mm}$ raster width, extrusion temperature $200^{\circ} \mathrm{C}$, and $40 \mathrm{~mm} / \mathrm{s}$ printing speed with nozzle $0.5 \mathrm{~mm}$ on Taz $6{ }^{\circledR}$ FDM system using PLA filament of $3.0 \mathrm{~mm}$. It was possible to print overhangs inclined with 60 degrees to $30 \mathrm{de}-$ grees from horizontal. Moreover, using the same settings, bridges extending by $10 \mathrm{~mm}$ to $40 \mathrm{~mm}$ were successfully fabricated without supports as shown in the Figure 6(c). More research effort is needed to optimize FDM for such features, as these limits can be further improved by optimizing the processing parameters.

In addition to overhangs, islands are another type of features that require a support during deposition. Islands, shown in Figure 7, are features that are not connected to the building bed and, for some time during the FDM process, are 


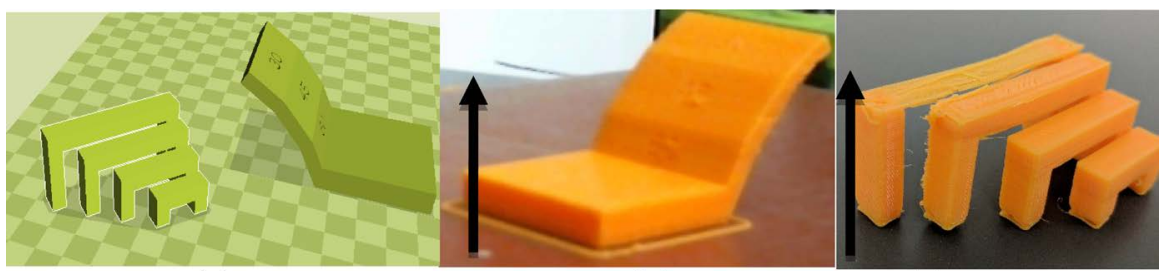

(a)

(b)

(c)

Figure 6. (a) STL files of overhangs and bridging tests loaded to Cura ${ }^{\circledR}$ slicer; (b) A successful print of overhangs with angles between 60 to 30 degrees; (c) A successful print of bridges with spans from $10 \mathrm{~mm}$ to $40 \mathrm{~mm}$. The black arrows indicate the building direction.

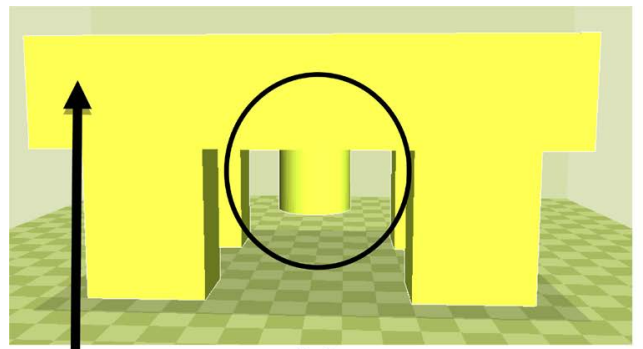

(a)

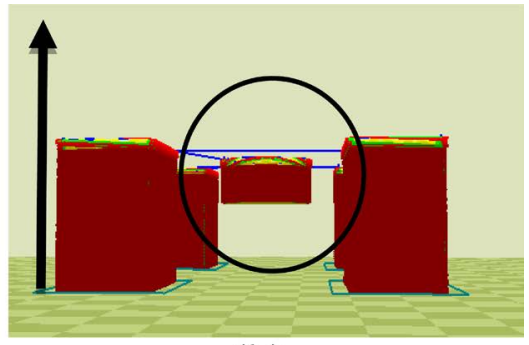

(b)

Figure 7. (a) A part with an island feature; (b) Same part in layers showing how that island is isolated during printing. The black arrow indicates the building direction.

isolated from the main body. However, if the part is fabricated in the opposite direction to what is illustrated in Figure 7, the need for the support will be eliminated as the island feature will have the flat top as a base. Thus, the orientation at which the part will be built might determine whether a part needs support or not.

FDM parts need a sufficient base area to ensure adhesion to the building bed. For example, spheres and curved sheets are very hard to fuse due to the small contact area with the building bed, which limits the possible orientations to build a given part with such features. In contrast, having a large base area increases the chances for warping.

Another feature that can be utilized using FDM is the ability to fuse around an insert objects. Although this feature is yet to be investigated thoroughly, in Kataria et al. [34] this feature was investigated for SLA and recently in Xiang "Anthony" Chen et al. [35] and Raymond R. Ma [36] work. It was shown that it can be applied for FDM as well.

In Klahna et al. [37] design guidelines for Snap-Fit Joints were given. The restrictions of AM were driven mainly from the anisotropy of the mechanical properties and the staircase effect on the surface of AM parts. The anisotropy may reduce the durability of load bearing features while the stair stepping hinders the movement of sliders, control rings and other kinematics. To incorporate these restrictions in the design, the build direction of the part at an early design phase should be determined carefully as in Figure 8 .

In conclusion, during the design process the limited possible orientation for such features should be considered to facilitate the printing process. Similarly, 


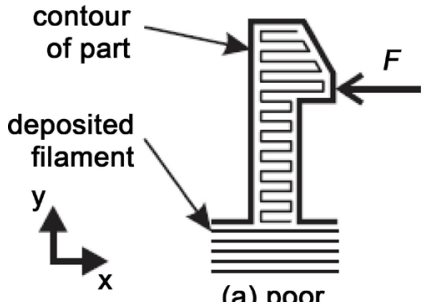

(a) poor

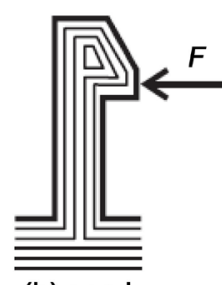

(b) good

Figure 8. (a) Poor building orientation; (b) Good building orientation [37].

for some shapes one is restricted to specific fusing orientations such as for cylinders, cones, and pyramids. If a part has many features in which no optimized orientation is possible, dividing the part into printable parts might be the only option.

\subsection{Dimensional Accuracy}

This term refers to how accurate the dimensions of the FDM part are in comparison to the input CAD drawing dimensions. The dimensional accuracy is affected by many parameters, mainly the $\mathrm{X}, \mathrm{Y}$, and $\mathrm{Z}$ positioning resolution, nozzle diameter and slicing thickness (layer thickness). The processing parameters during the printing process significantly affect the accuracy of the part as it can affect shrinkage, bonding and warping [38]-[42]. This is very important for assemblies. In a study for components benchmarking, it was found that $97.7 \%$ of the dimensions were in $\pm 0.50 \mathrm{~mm}$ tolerance range and most of them were positive indicating a larger fabricated features than in the input CAD model [31].

In a study done by the authors [17], a total of $18 \times 3$ ASTM D683 specimens were fabricated using variant processing parameters. Each specimen was created in a set of three copies to check for the repeatability of the FDM process for same set of processing parameters.

The specimens were measured for their width, thickness and length. It was found that fabricating the part at different orientations affect the deviation in the dimensions. In addition, when the total dimension of the part was equal to an integer multiple of the layer thickness, a lower dimensional error is resulted.

For example, to create a solid cylindrical part with $25.4 \mathrm{~mm}$ (1 inch) height using FDM with a common nozzle diameter of $0.4 \mathrm{~mm}$. The optimized cylindrical height to increase the dimensional accuracy will be either $25.5 \mathrm{~mm}$ or 25.2 $\mathrm{mm}$ instead of $25.4 \mathrm{~mm}$ if the slicing thickness used is $0.30 \mathrm{~mm}$.

The dimensional accuracy is influenced by the processing parameters used during fabrication. To investigate the influence of some of these parameters in this work, a total of 8 tensile test specimens fabricated according to ASTM D638 type IV where created using different processing parameters. Four of the specimens, where fabricated using different extrusion temperatures and the rest of the processing parameters, were fixed. The remaining four samples were printed using different layer thicknesses and the rest of the processing parameters were the same for each sample. Each specimen was measured at the locations shown in Figure 9 and were compared to the dimensions of the input CAD model. 


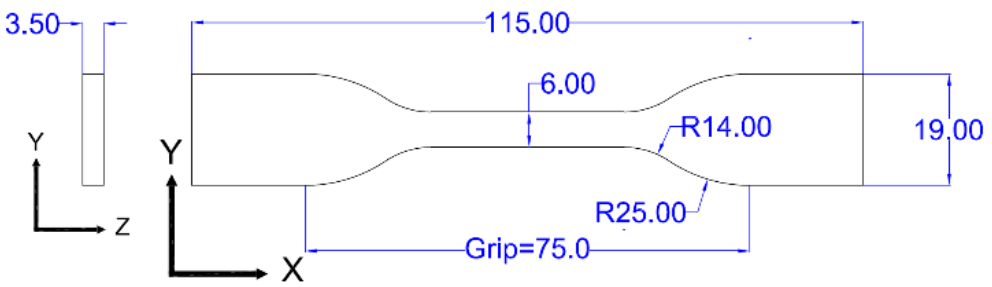

(a)

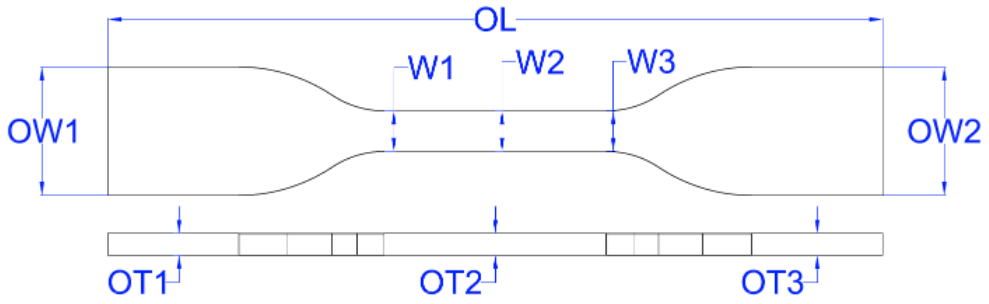

(b)

Figure 9. Fabricated ASTM specimen type IV dimension. Indicated arrows refer to the locations of the measurements taken for dimensional accuracy comparison: (a) The original dimension of the CAD file; (b) The measurement locations for the FDM samples.

Table 2. Measured dimensions in samples shown in Figure 9 for FDM dimensional accuracy study.

\begin{tabular}{ccc}
\hline Dimension Name & Measured Points & Averaged Value \\
\hline Necking Width & W1, W2, and W3 & W \\
Sample Width & OW1, OW2 & OW \\
Sample Thickness & OT1, OT2, OT3 & T \\
\hline
\end{tabular}

The measurements are averaged based on Table 2. The widths at locations W1, W2, and W3 were averaged as W and similarly for OWs and OTs, the dimensional error figures were generated as shown in Figure 10. From Figure 10(a) we can see that by increasing the extrusion temperature the dimensional error increases, which can be due to the uncontrolled flow of the extruded raster. Similarly, from Figure 10(b) reducing the layer thickness resulted in a reduction in the dimensional error parallel to that building direction, which is the thickness of the specimens.

This error can be avoided by selecting a layer thickness that is compatible with that dimension. For example, in Figure 10(b) we can see that the dimensional error at $0.10 \mathrm{~mm}$ and $0.25 \mathrm{~mm}$ layer height gave the smallest errors in the thickness of the tensile specimens. This occurred because both $0.10 \mathrm{~mm}$ and $0.25 \mathrm{~mm}$ can produce the thickness of the specimens using an integer number of layers, which is 35 layers for the $0.10 \mathrm{~mm}$ layer height and 14 layers for the $0.25 \mathrm{~mm}$ layer height. From Figure 10(c) it is indicated that the printing direction as described in Figure 9(a) affects the linear dimensional accuracy. This can be related to the variation between the raster width and the layer thickness in addition to the variation in the positioning accuracy of the nozzle between the $x-y$ plan and the $\mathrm{z}$ direction. 


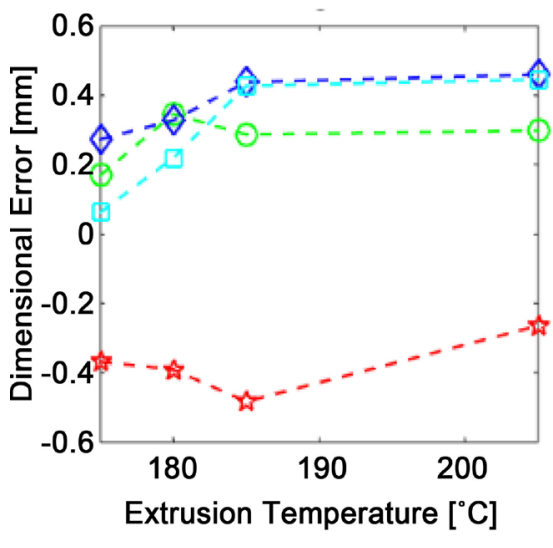

(a)

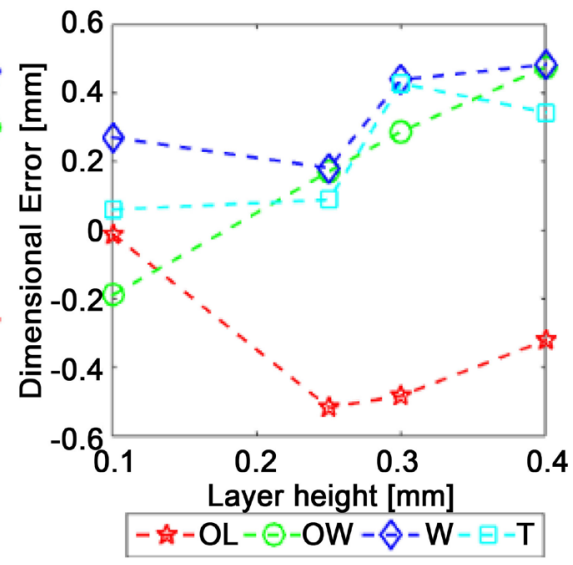

(b)

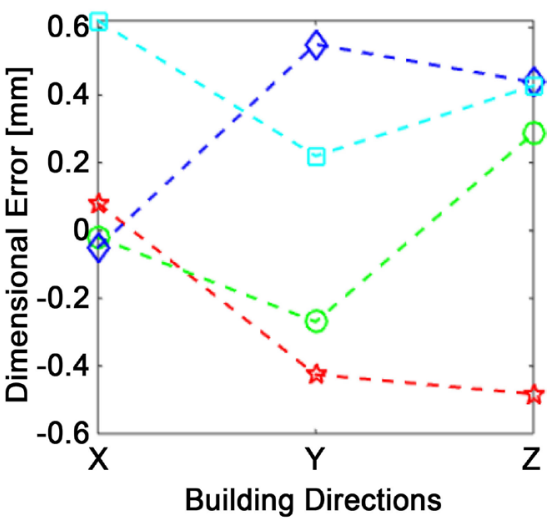

(c)

OL: Overall Length, OW: Average of overall width OW1 and OW2. T: Average of Thicknesses OT1, OT2 and OT3. W: Average of Widths W1, W2 and W3.

Figure 10. The influence of extrusion temperature, layer thickness and building direction on the resulted dimensional error.

During the design phase, clearances should be assigned between any meshing parts. For example, a pin should be fabricated with a slightly smaller diameter, while the hole where the pin is assembled to, should have a slightly larger inner diameter to facilitate the assembly. The Geneva mechanism was taken as a case study to investigate clearances for assembled parts in this work. To find the correct clearance firstly, a fitting calibration test was done as shown in Figure 11. Six small cylinders with diameters ranging from $4.00 \mathrm{~mm}$ to $1.50 \mathrm{~mm}$ in 0.50 increments were printed and 6 corresponding holes were printed. However, for the holes the samples were repeated with different assigned clearances ranging from $0.10 \mathrm{~mm}$ to $0.50 \mathrm{~mm}$ in $0.10 \mathrm{~mm}$ increments. It was found that the cylinders fit forcibly in the holes with $0.30 \mathrm{~mm}$ clearance and easily in the $0.40 \mathrm{~mm}$ while fitting loosely in the $0.50 \mathrm{~mm}$. The $0.30 \mathrm{~mm}$ was used for the fixed assemblies in the Geneva mechanism such as the crank and its shaft, while the $0.40 \mathrm{~mm}$ was used for the moving joints such as the Geneva wheel and its driving pin, where the $5.0 \mathrm{~mm}$ slot was increased to $5.40 \mathrm{~mm}$ as shown in Figure 12.

\subsection{Surface Roughness and Surface Finish}

FDM parts usually have high surface roughness and require surface finishing to get smooth surfaces that are comparable to the surface of injection molding parts. The surface roughness of a part is important in the case of FDM assemblies, especially for moving joints as the poor surface finish will affect the performance of the joint due to high friction. This can cause early part or assembly failure. The processing parameters of FDM directly affect the surface roughness of fabricated parts. FDM processing parameters highly influence the staircase effect such as the extrusion temperature, extrusion width, layer thickness and building orientation [43]-[48]. Typical values for surface roughness of a flat surface that does not suffer from staircase is $\mathrm{Ra}=1.86-22.48 \mu \mathrm{m}$ [49]. Whereas, for inclined surfaces suffering from staircase effect, the layer thickness and inclination angle play a great role [44]. It was shown that inclination angles that are 


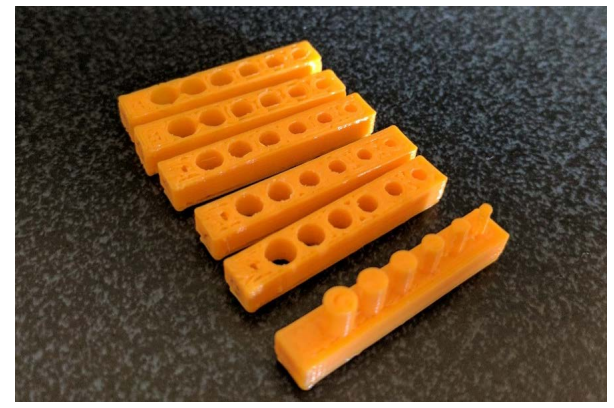

Figure 11. Fitting calibration test to find the best clearance needed.

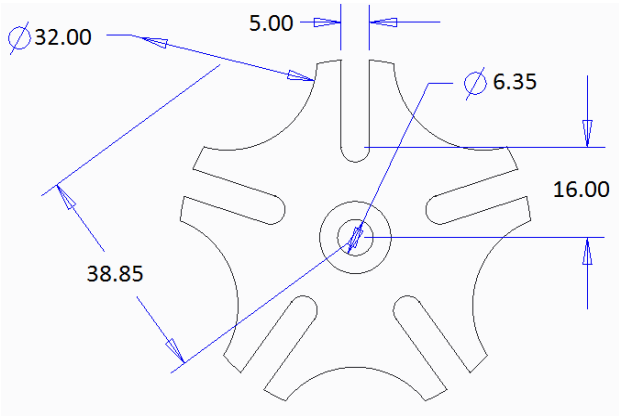

(a)

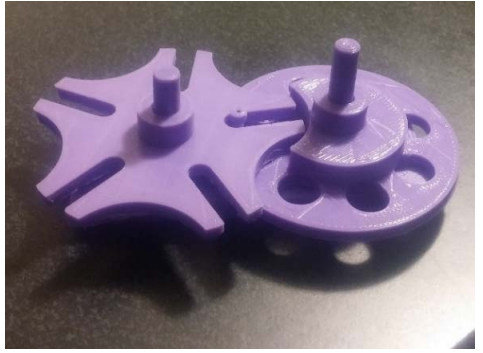

(b)

Figure 12. (a) Nominal dimensions of the Geneva wheel; (b) Functional FDM Geneva wheel with optimized clearances.

close to $30^{\circ}$ have a higher surface roughness. In addition, increasing layer thickness, will increase the part's surface roughness. A surface at $30^{\circ}$ angle with layer thickness of $0.178 \mathrm{~mm}$ will have a surface roughness around $40 \mu \mathrm{m}$. If the surface finishing is an important aspect in the part, then the feasible building orientation will be a multi objective optimization problem. Another way to get a good surface finish is by choosing a chemically treatable filament such as ABS and post process the fused part [24].

\subsection{Fusing Time}

One of the advantages of AM technologies is that they eliminate the lead time needed until the production starts for mold design and production or setting up the production line. However, the fused process itself is very slow. Fusing time is stimulated by many factors such as the speed of the axis controlling the extruder, layer thickness and building orientation. Most commercial FDM printers have extruders that can move at speeds up to $200 \mathrm{~mm} / \mathrm{s}$ or more. However, during extrusion a speed of $80 \mathrm{~mm} / \mathrm{s}$ or lower is usually used to enhance the parts' quality. By orienting the part's largest surface area as parallel to the layer plane, the printing time can be minimized as shown in Figure 13. The estimated fabricating time for the same sample can be significantly reduced by orientation choice.

Fusing time is also driven by the layer thickness; the smaller the layer thickness is the longer the fusing time will be. In addition, avoiding the need for supports can reduce the fusing time significantly. That can be done either by eliminating unnecessary features that need support or by choosing an appropriate 


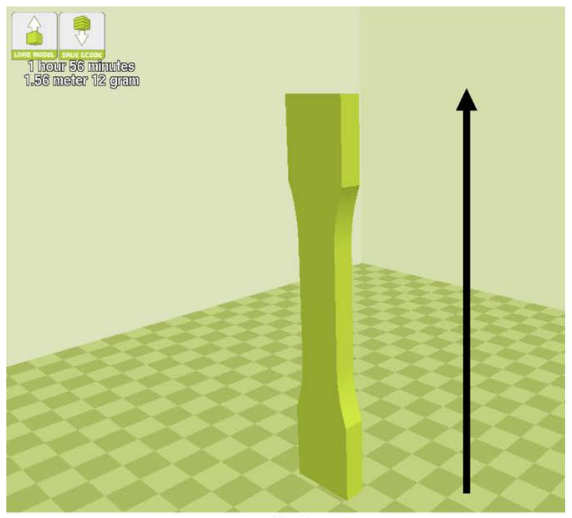

(a)

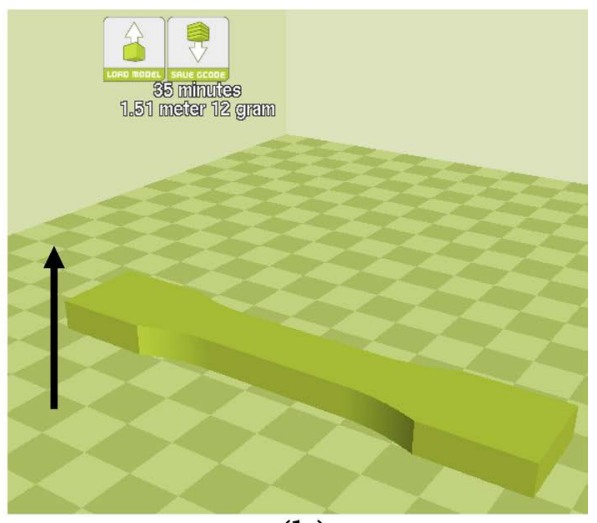

(b)

Figure 13. (a) A specimen fused vertically with 2 hours fusing time indicated; (b) The same specimen printed horizontally with 32 minutes fused time. By orientating the largest surface of a part parallel to the layering direction, the fusing time can be reduced. Black arrows indicate the building direction.

building orientation that minimizes the need for support. In Teitelbaum et al. [50] many guidelines for choosing the appropriate building direction to minimize printing time were reported such as 1) build object with largest surface on bottom; 2) Maximize layer thickness; 3) Build holes facing upward; 4) Minimize number of overhangs; 5) Minimize the height by making the largest dimension parallel to the building bed.

\subsection{Load Criteria}

Due to the nature of AM, parts suffer from high anisotropy in their mechanical properties. The designer should consider this anisotropy, which is highly affected by the processing parameters during the fusing. Therefore, it is important to consider anisotropy [51] [52] [53] [54] in the design process to optimize the functionality of the FDM produced parts [55]. To have strong parts, it is recommended to reduce the number of layers. That can be done by orienting the part flat [56] on its larger surface area as shown in Figure 13(b).

Increasing the layer thickness will yield a stronger part as well. It should be noted that FDM parts are usually stronger along the layer direction and weaker along the building direction, which is indicated by having a higher tensile strength and higher young's modulus [17]. For that reason, the loading condition should be considered while designing the part to avoid and modify geometries that dictate building directions that might compromise the ability of the part to bear loads as desired.

\subsection{Cost}

Production cost is a primary factor that must be considered during the design stage. The cost of the FDM parts depends primarily on the material and the power consumed during fabrication. The material consumed can be divided into the part's material and the construction material such as the material used for supports, rafts and brims which are for adhesion and warping reduction. The 
material needed for the part should be optimized by optimizing the part's topology. The optimization takes into consideration the loading requirements and the part's intended function. The construction material can be minimized by optimizing the building parameters such as building orientation which could reduce the need for supports. Constructional materials consumption can be reduced by using appropriately heated bed to minimize the need for rafts and brims. As a result, the building orientation of FDM parts is strongly correlated to cost [56]. On the other hand, the consumed power depends primarily on some processing parameters such as the nozzle diameter, the heated bed temperature and the time needed to finish the build.

\subsection{Defects}

Most FDM defects can be eliminated or reduced by using a good combination of processing parameters. However, some types of defects need to be considered during the design process as they might affect the performance of the part. The first defect is oozing or stringing, shown in Figure 14(a), which occurs when traces of small strings of polymer are left behind the nozzle when it is not extruding. This defect can be minimized by reducing the extrusion temperature and increasing the retraction of the filament during travel times. However, this defect can be persistent when fabricating features separated by small gaps. Strings caused by oozing can be mechanically removed or by chemical surface treatment for some materials. However, that can be challenging to accomplish for internal features and joints.

Another important defect is under extrusion, shown in Figure 14(b), which happens when the nozzle is not extruding enough plastic while filling the parts. Therefore, there are unintended gaps left between the contours and infill lines. This defect affects the part's integrity and makes it weaker. In addition to rendering the defective parts not usable for fluid application since they are not water tight. This defect can be eliminated by increasing the extruded plastic, which can be done by various ways using commercial and open source slicers such as correct-

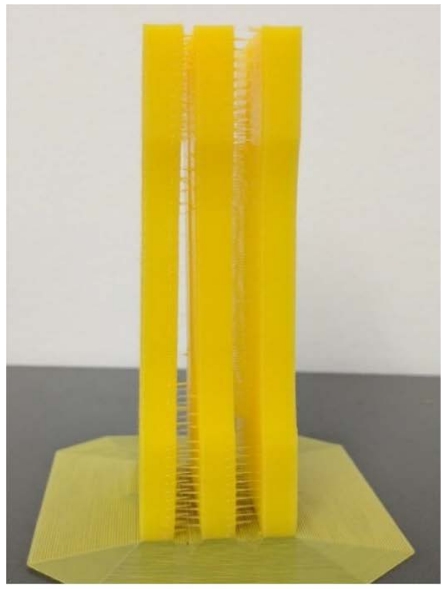

(a)

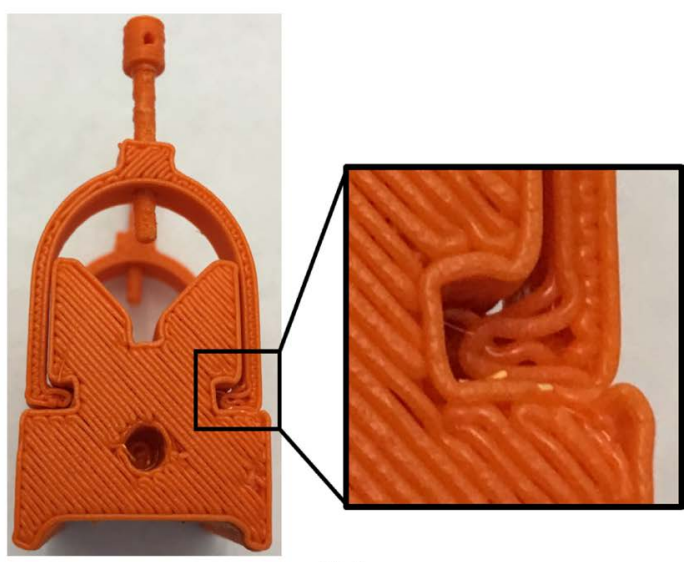

(b)

Figure 14. Common defects: (a) Stringing; (b) Under extrusion. 
ing the extrusion multiplier or the entered filament diameter. Nevertheless, even after eliminating the under-extrusion defect, there is a gap in the literature about the pressures that FDM parts can handle compared to traditional manufactured parts. Some work presented an experimental methodology to investigate the main factors of profile errors in FDM parts [57]. A spiral shaped profile with cylinders with different radiuses where fused using different values of contour widths, contour depths, part raster widths and raster angles. It was found that contour width has the most obvious effect on both issues. The larger the width is, the better the profile accuracy is. On the other hand, a narrow width results in a dense and good appearance of the aperture area on the surface layer.

\section{Case Study}

To demonstrate the design considerations for FDM, a support bracket shown in Figure 15(a) is redesigned to be fabricated by FDM. The original support bracket was constructed from 3 steel parts; a circular rod, a rectangular bar and a 3.5 $\mathrm{mm}$ thick plate that holds the pipe. In the original set up, each support was bearing $2.25 \mathrm{Kg}$ due to the supported pipe weight. A CAD model of the original support bracket was created to simulate the load and to identify the locations of high and low stresses. For simulation purposes, a high safety factor was added to the load resulting with simulated load of $35 \mathrm{Kg}$. The fixed end was constrained with fixed displacement boundary condition [58]. The simulation results, shown in Figure 16, identified the locations of the maximum stress as the top and bottom surface of the cylindrical rod at the fixed end in addition to the corners between the plate and the rectangular bar where a huge change in cross section caused stress concentration in that region.

To redesign the support bracket for FDM, the design considerations discussed above are taken into consideration as follows: The CAD tool used for the drawings was Creo 3.0 $0^{\circledR}$. For the FEA, ANSYS ${ }^{\circledR}$ Mechanical 17.0 with the free ACT topology optimization extension, which will enable free form design. The material options are limited to ABS, Nylon and PLA due to availability and the li-

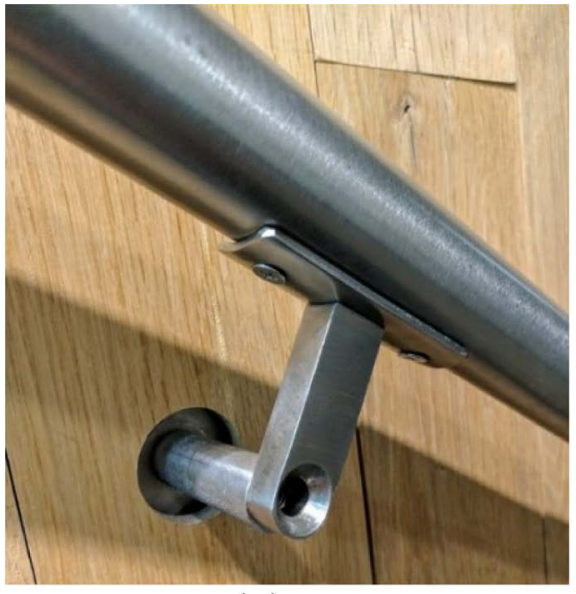

(a)

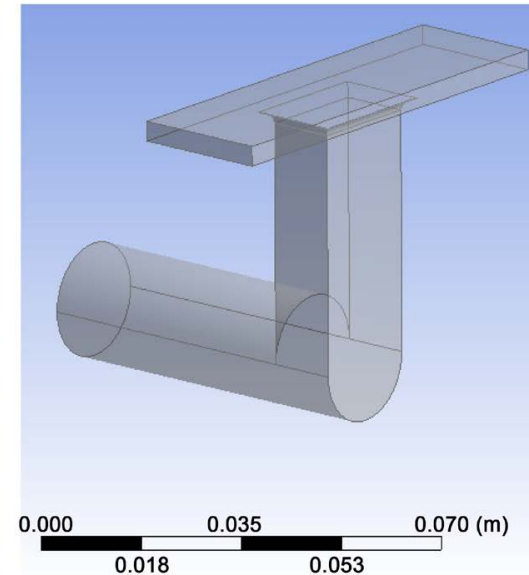

(b)

Figure 15. Support bracket: (a) Original design; (b) Its CAD model. 


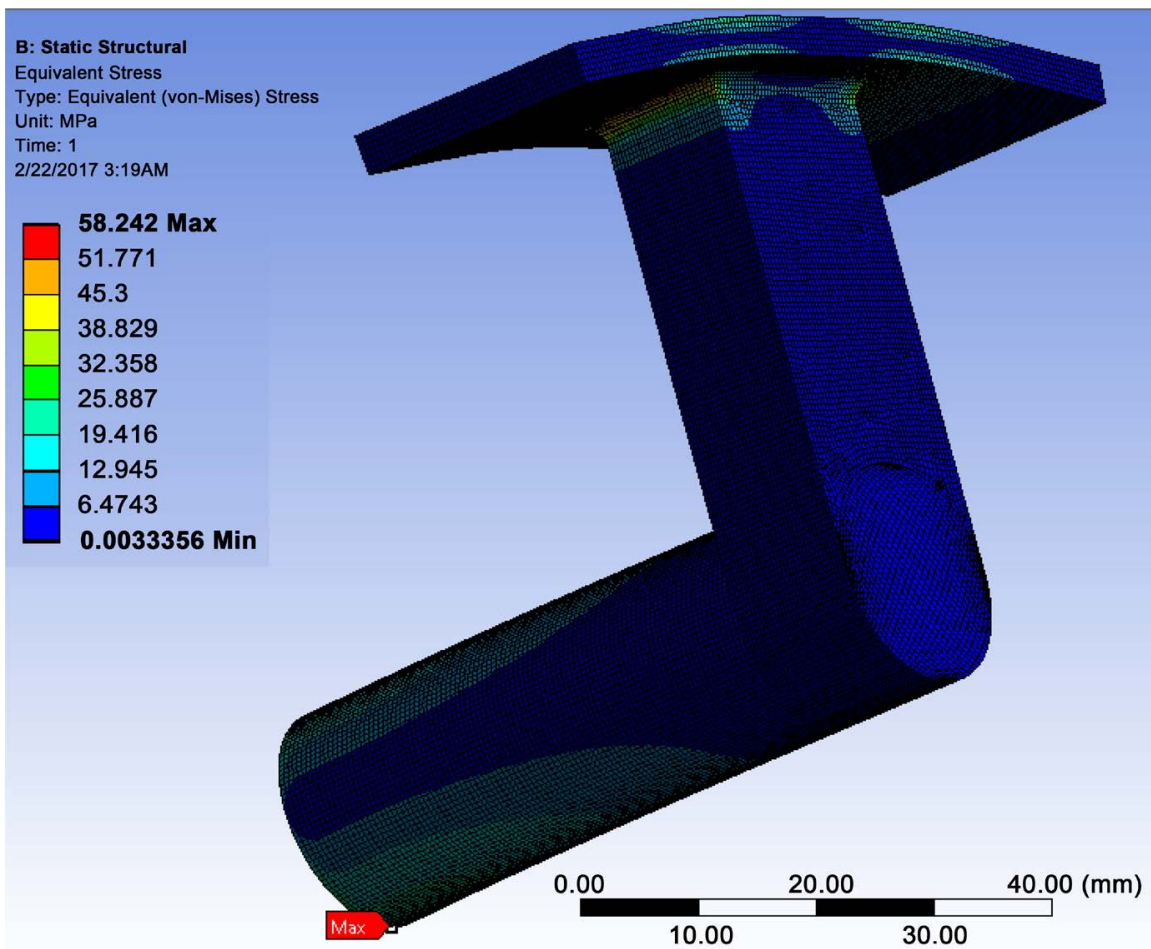

Figure 16. Stress results of the original support bracket.

mited extrusion temperature up to $300^{\circ} \mathrm{C}$. PLA was chosen over ABS and Nylon due to its higher modulus of elasticity and strength. The envelop dimensions of the original support bracket are $(75 \mathrm{~mm}, 74 \mathrm{~mm}, 60 \mathrm{~mm})$ which are well within the building volume of the TAZ6 ${ }^{\circledR}$ equipment (i.e. $280 \mathrm{x}, 280 \mathrm{y}, 250 \mathrm{z}$ all in mm). The modified design is not to cross these envelop dimensions to remain functional. The support bracket can be fused while keeping the cylinder rod in its original shape. However, that will limit the building direction to be aligned with the cylinder rod's axis, which will reduce the ability of the part to bear the bending stress developed normal to the cross section of the cylinder. Therefore, the cylindrical cross section is replaced by a square, which can be fused in many directions. The initial FDM suggested design is shown in Figure 17(a). The plate is made thicker and the rectangular bar is replaced by a varying cross section rectangular shape to eliminate the stress concentration at the corner between the plate and the rectangular bar in the original support bracket. The angle of the varying cross section region is designed to be less than 45 degrees measured from the normal direction to the cross section to avoid the need for support, which will reduce material and time if fabricated in the orientation shown in Figure 18.

The initial design has no small features that cannot be fused. In addition, the surface roughness of the part has no effect on its function. And because of the elimination of assembly for the part, accurate tolerances are not significant to this design.

The initial design was used to analyze the load of $35 \mathrm{Kg}$. It can be seen from Figure 17(b) looking at the sectioned support bracket there are many regions 


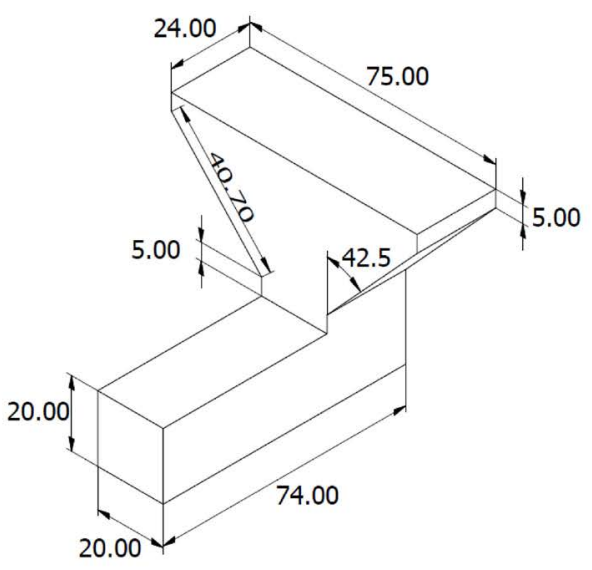

(a)

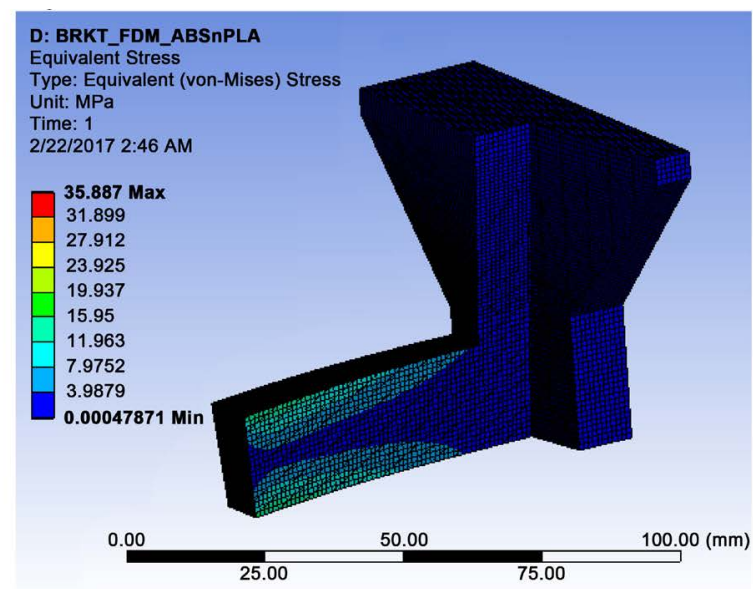

(b)

Figure 17. (a) Initial design of the FDM pipe support; (b) Von Mises stresses distribution results from FEA.

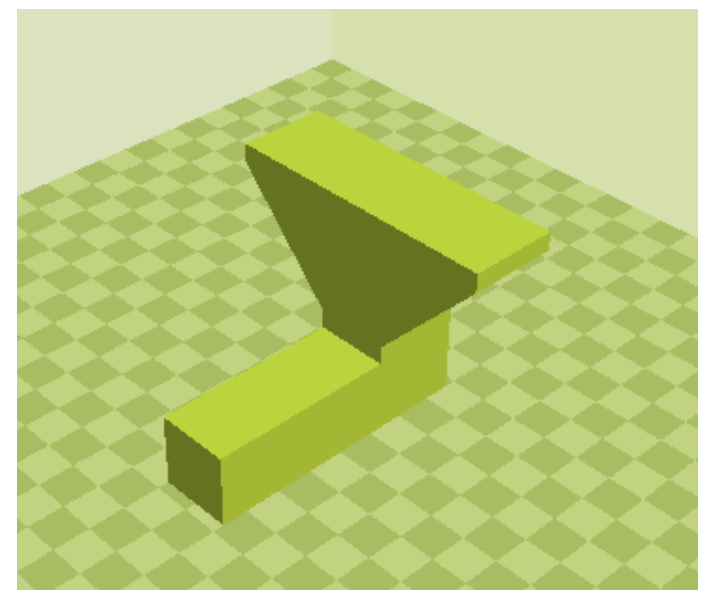

Figure 18. Suggested building direction for initial support bracket design indicated by the black arrow.

bearing very small load. These regions indicate an overdesigned part with unnecessary excess material. Therefore, topology optimization is required to further improve the design and make it more efficient. The topology optimization was done using ANSYS ACT Topology Optimization ${ }^{\circledR}$. The objective of the optimization was to minimize the compliance. The whole part was subjected to the optimization except the fixed support surface, the area where the load was applied and the bottom of the part to ensure keeping a flat surface for manufacturability. The optimization constraints applied were minimum member size of $5 \mathrm{~mm}$, volume percentage of $50.0 \%$, global stress of $40 \mathrm{MPa}$ and a maximum deformation of $1.5 \mathrm{~mm}$. The minimum member size constraint was used to ensure no small features were created for better manufacturability.

The resulted topologically optimized design is shown in Figure 19. The suggested design can be fabricated without supports, which was verified using the following sittings, layer height of $0.20 \mathrm{~mm}, 2$ shells or contours, $100 \%$ infill percentage, $50 \mathrm{~mm} / \mathrm{s}$ print speed, extrusion temperature of $200^{\circ} \mathrm{C}$, bed temperature 
of $60^{\circ} \mathrm{C}$ for better adhesion, without supports. The FDM part was printed using PLA $3.00 \mathrm{~mm}$ filament on TAZ 6 with a $0.50 \mathrm{~mm}$ nozzle. The part was printed in the orientation indicated in Figure 19(c).

Another design for the support bracket can be show in Figure 20(a). It is inspired by the topologically optimized design while remaining astatic. This design has some regions without support as shown in Figure 20(b), but can be bridged without support. The design was further verified using FEA and by FDM shown in Figure 21. The FDM part was printed using PLA $3.00 \mathrm{~mm}$ filament on TAZ 6 with a $0.50 \mathrm{~mm}$ nozzle. The processing parameters used were, layer height of $0.20 \mathrm{~mm}, 2$ shells or contours, $100 \%$ infill percentage, $50 \mathrm{~mm} / \mathrm{s}$ print speed, extrusion temperature of $200^{\circ} \mathrm{C}$, bed temperature of $60^{\circ} \mathrm{C}$ for better adhesion, without supports. The part was printed in the orientation indicated in Figure 21(b). This orientation was chosen because it will enable printing the part without supports and will yield layers oriented perfectly to handle the load applied. The top region will be subjected to compression normal to the layers and on the fixed support the bending will create stress parallel to the layers' orientations. Since the part does not have any curves, the stair effect was minimized with layer height $0.20 \mathrm{~mm}$, which optimizes between the stair effect and printing time. The printing time was 5 hours and 20 minutes including the heating and auto bed level.

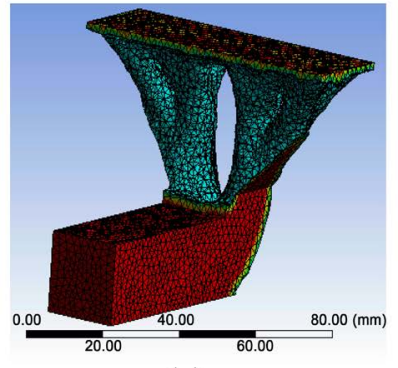

(a)

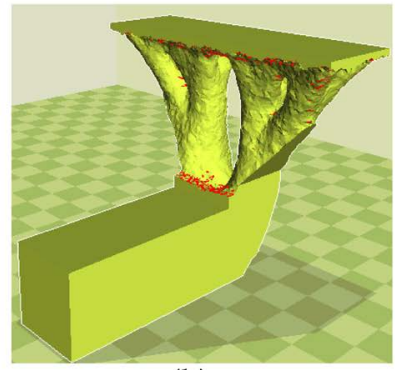

(b)

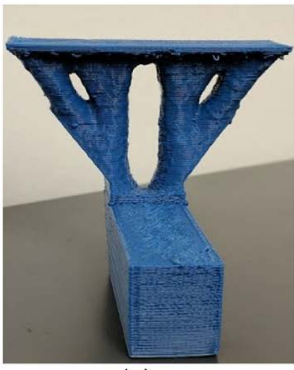

(c)

Figure 19. (a) Topology optimized support bracket; (b) STL file with red regions highlighting overhanging with angle over 45 degrees; (c) The final topologically optimized support bracket produced by FDM.

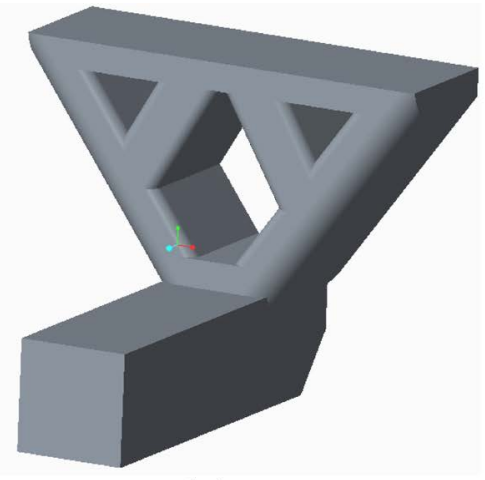

(a)

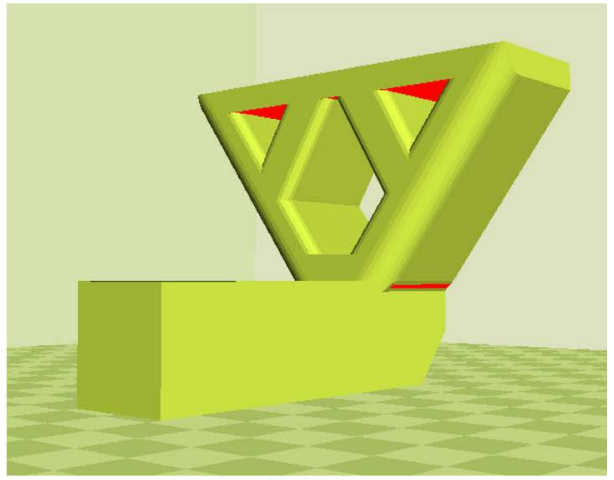

(b)

Figure 20. (a) CAD drawing of a second design inspired by the topologically optimized design; (b) The design highlighting regions that might need support in red color. 

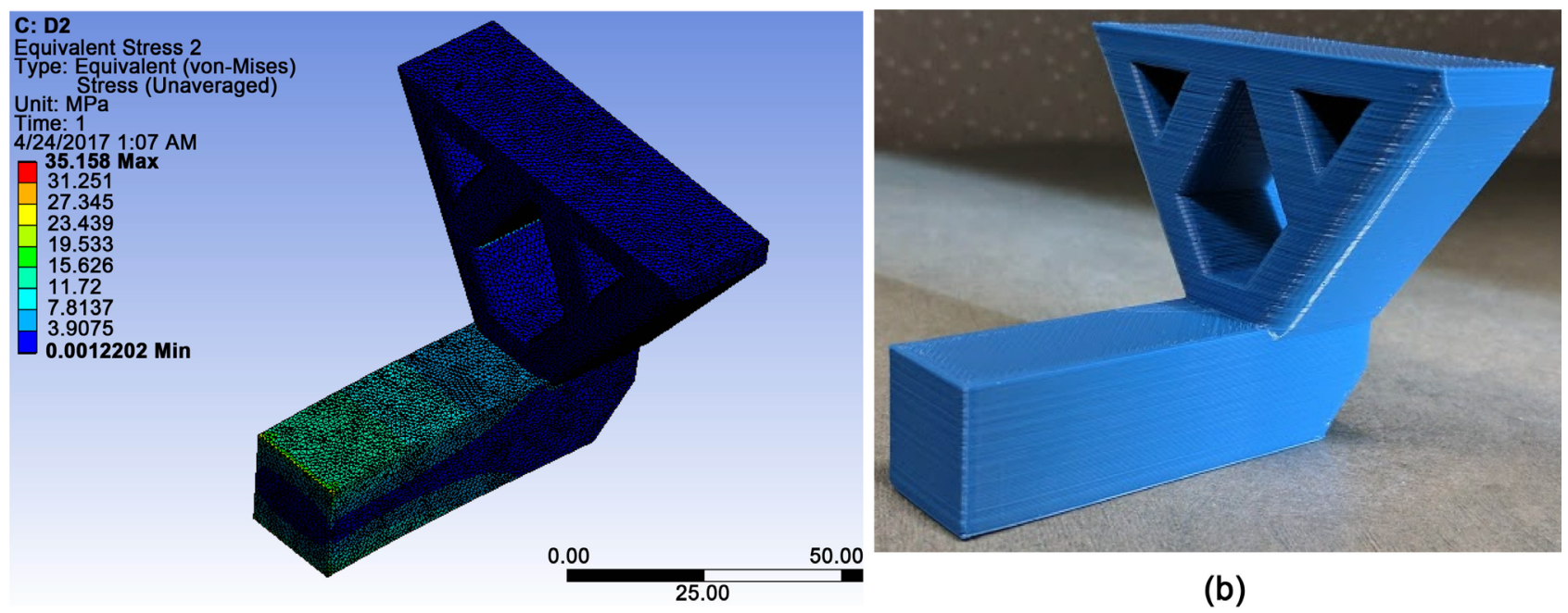

(a)

Figure 21. Verification of the design using (a) FEA and (b) FDM.

\section{Conclusions}

This paper presents the design considerations for FDM from Design for manufacturing aspect. It discusses the limitations of FDM in aspects such as building volume, limited material options, lack of data packages for design and simulation, and discussed unfused features such as very small details, and islands. This work provides the typical dimensional accuracies, surface roughness values and typical clearance values for assemblies. In addition, it delivers benchmarks for fused angles and lengths of overhangs and bridges without supports. This paper summarizes the major guidelines that designers are recommended to follow while creating the parts and fabricating them to optimize the topology, building time and the mechanical properties of the part. Authors presents two experimental studies on the dimensional accuracy of the FDM parts compared to the input CAD model, in addition to the effect of the FDM processing parameters on the modulus of elasticity for PLA samples.

Finally, a case study is presented following the design considerations to redesign a support bracket to be fabricated by FDM. The case study demonstrated the advantages and disadvantages of AM and considered FEA and topological optimization to modify the metal support bracket into a PLA support bracket suitable for FDM. In conclusion, it is important to consider the limitations of FDM and the influence of processing parameters on the quality of FDM parts in early designs stages. This allows better process optimization during production, which might lead to more objectives satisfied compared to optimizing the processing parameters for designs optimized for traditional manufacturing methods.

Currently, FDM is still an immature manufacturing technology for high production volumes and there is still room for improvement and gaps in literature to be filled to improve the DFAM. This work provides a summary of revised literature, Table 3 , in terms of focus area and design consideration. 


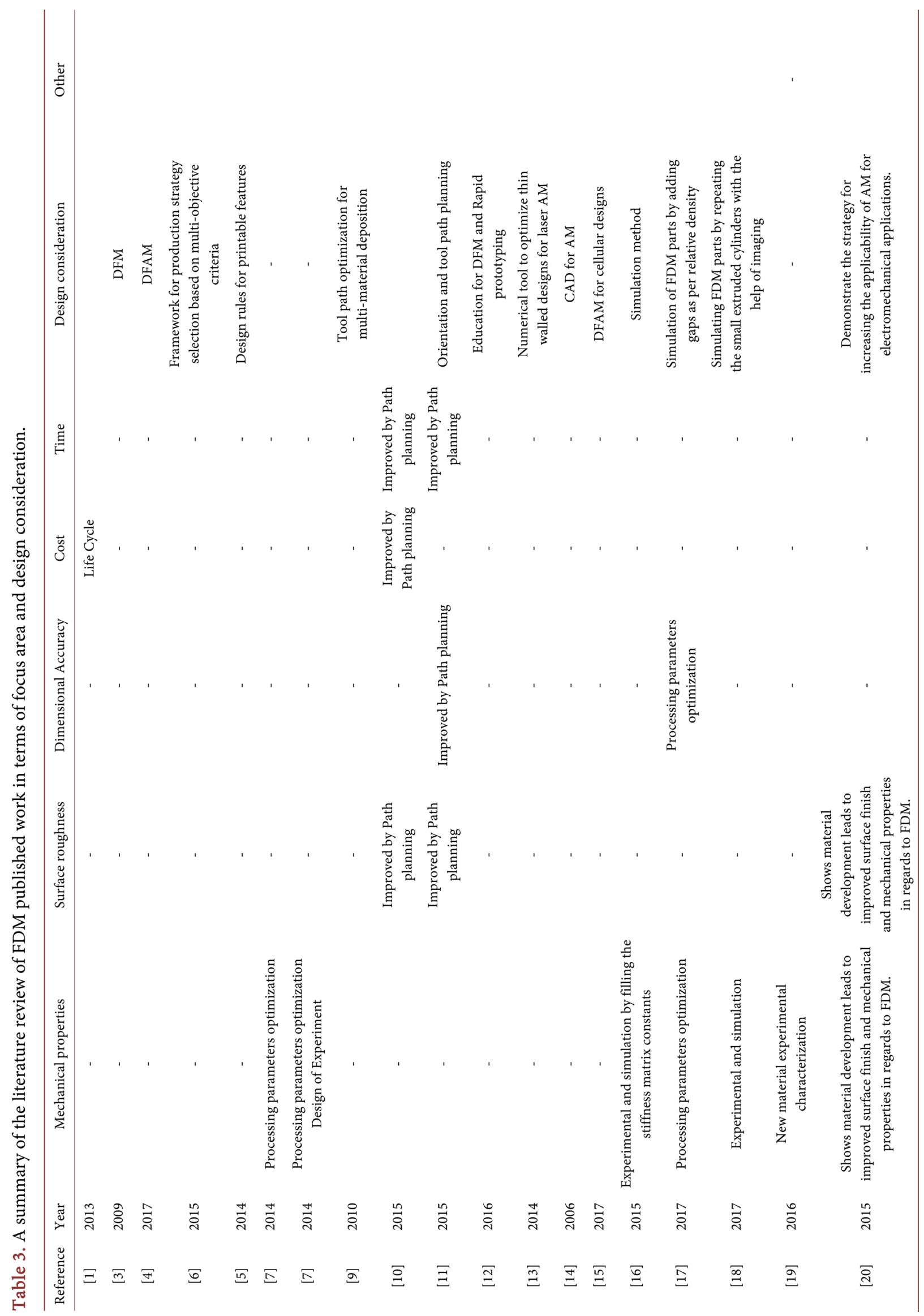




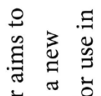

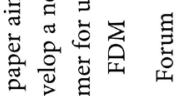

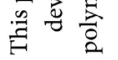

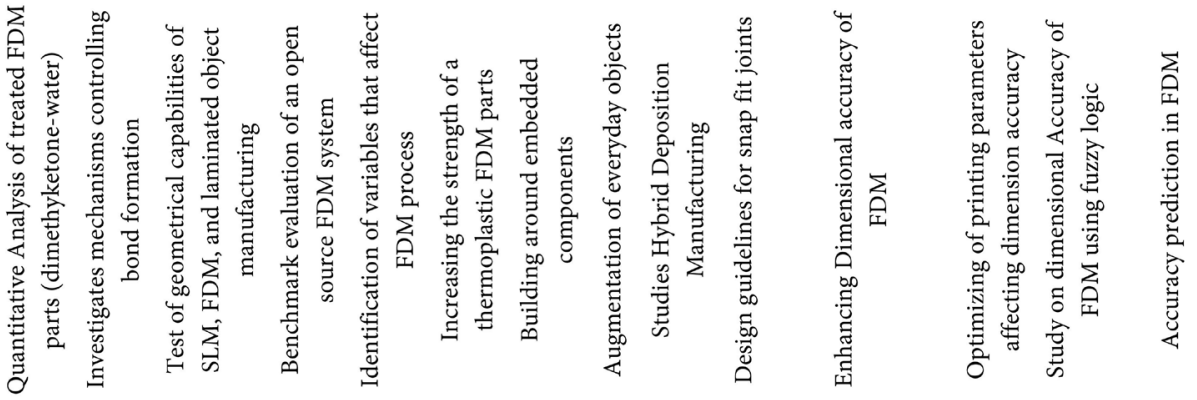

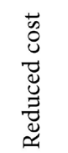
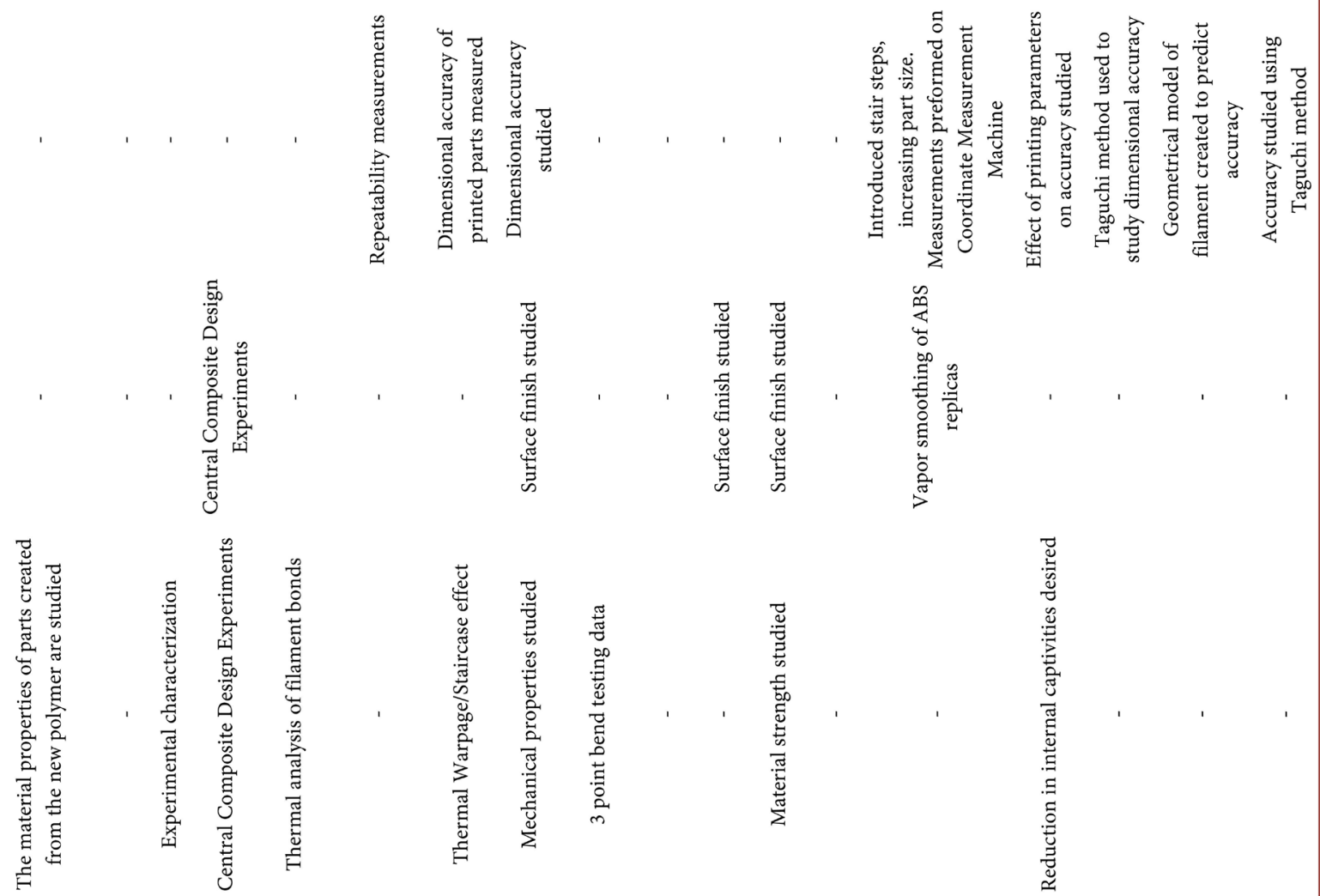

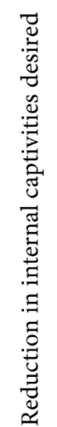

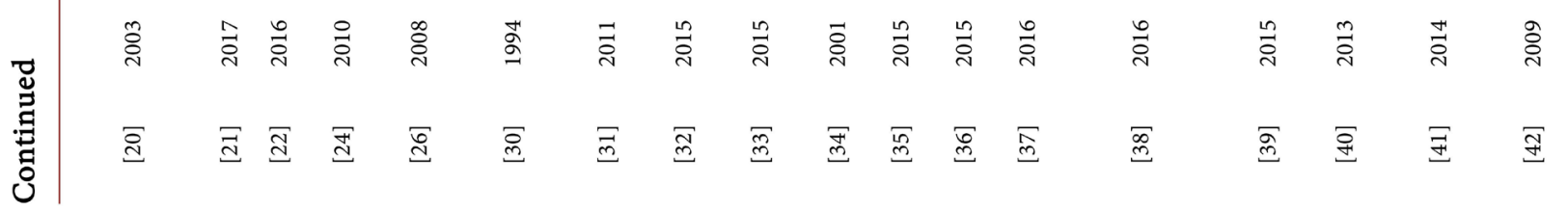



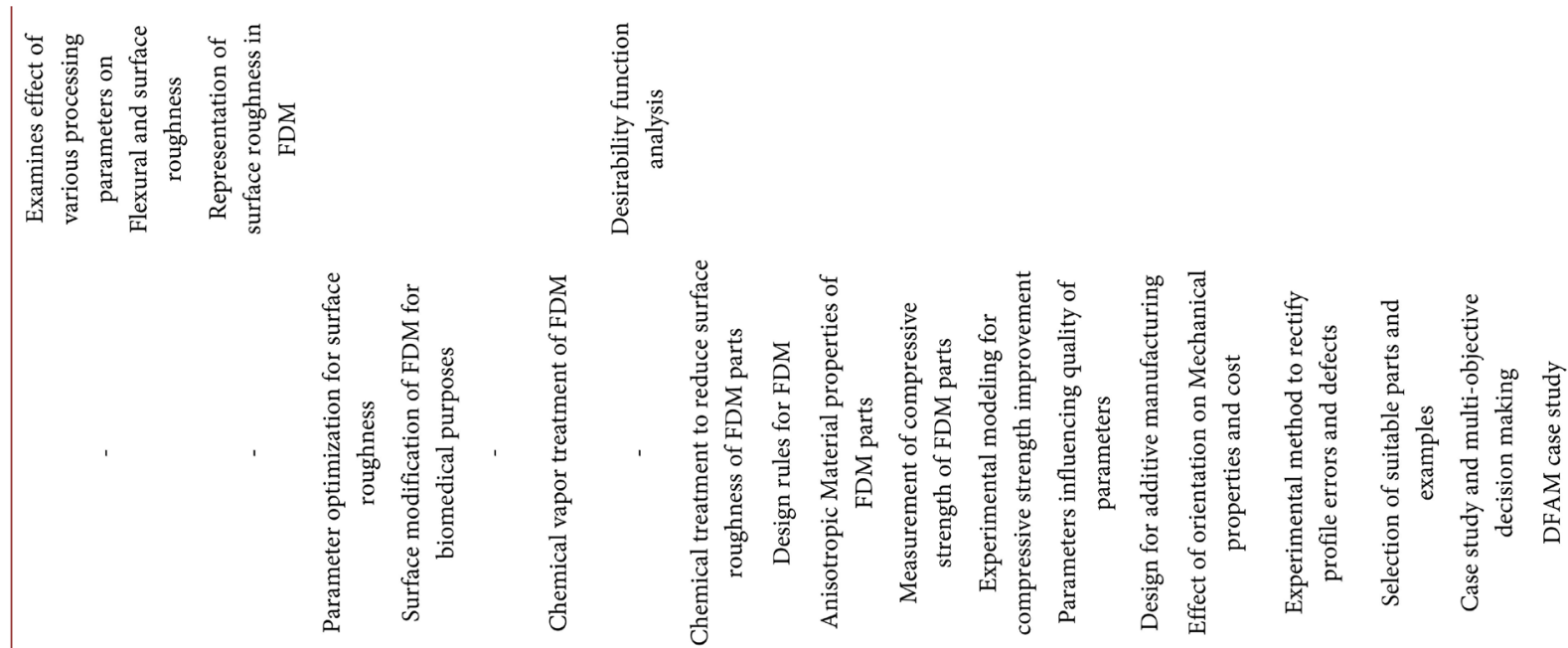

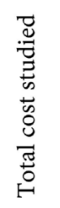

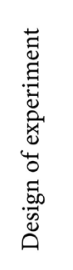
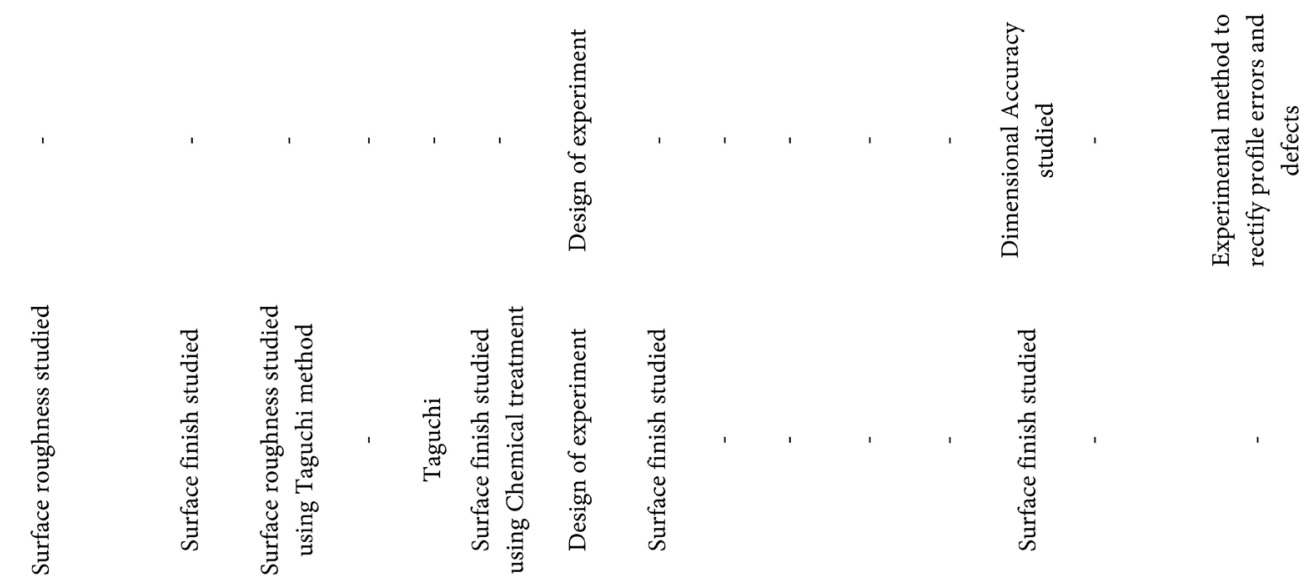

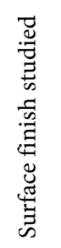

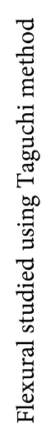
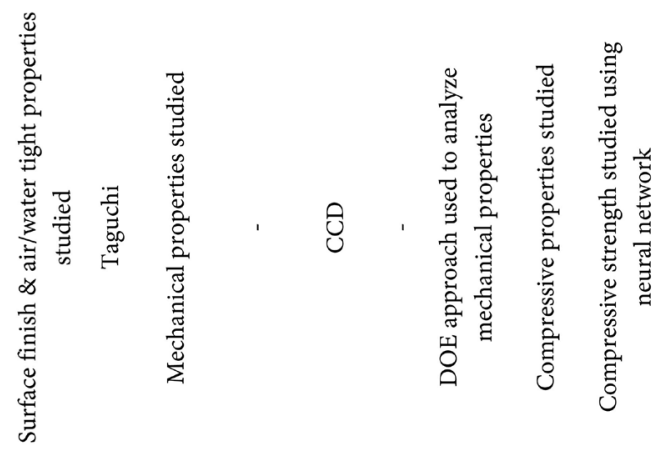

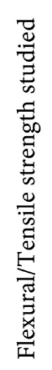

苞

กั่

苟 ํㅜㅇ

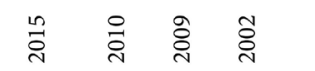

ฮั่ รี

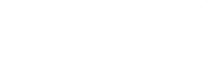

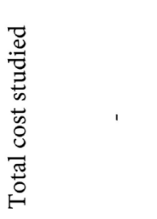

昰早里

焉焉焉 


\section{Acknowledgements}

This research was supported by the Hellman Foundation through Hellman Faculty FellowshipGrant-55253 for 2016.

\section{References}

[1] Wittbrodt, B.T., Glover, A.G., Laureto, J., Anzalone, G.C., Oppliger, D., Irwin, J.L. and Pearce, J.M. (2013) Life-Cycle Economic Analysis of Distributed Manufacturing with Open-Source 3-D Printers. Mechatronics, 23, 713-726. https://doi.org/10.1016/j.mechatronics.2013.06.002

[2] Poli, C. (2001) Design for Manufacturing: A Structured Approach by Corrado Poli. Elsevier Science \& Technology Books, Amsterdam.

[3] Tomiyama, T., Gu, P. Jin, Y., Lutters, D., Kind, C. and Kimura, F. (2009) Design Methodologies Industrial and Educational Applications. Manufacturing Technology Journal, 58, 543-565. https://doi.org/10.1016/j.cirp.2009.09.003

[4] Kumke, M., Watschke, H. and Vietor, T. (2017) A New Methodological Framework for Design for Additive Manufacturing. Virtual and Physical Prototyping, 2759, $2-20$.

[5] Adam, G.A.O. and Zimmer, D. (2014) Design for Additive Manufacturing-Element Transitions and Aggregated Structures. CIRP Journal of Manufacturing Science and Technology, 7, 20-28. https://doi.org/10.1016/j.cirpj.2013.10.001

[6] Achillas, C., Aidonis, D., Iakovou, E., Thymianidis, M. and Tzetzis, D. (2015) A Methodological Framework for the Inclusion of Modern Additive Manufacturing into the Production Portfolio of a Focused Factory. Journal of Manufacturing Systems, 37, 328-339. https://doi.org/10.1016/j.jmsy.2014.07.014

[7] Onwubolu, G.C. and Rayegani, F. (2014) Characterization and Optimization of Mechanical Properties of ABS Parts Manufactured by the Fused Deposition Modelling Process. International Journal of Manufacturing Engineering, 2014, 13. https://doi.org/10.1155/2014/598531

[8] Rayegani, F. and Onwubolu, G.C. (2014) Fused Deposition Modelling (Fdm) Process Parameter Prediction and Optimization Using Group Method for Data Handling (Gmdh) and Differential Evolution (De). The International Journal of Advanced Manufacturing Technology, 73, 509-519. https://doi.org/10.1007/s00170-014-5835-2

[9] Choi, S.H. and Zhu, W.K. (2010) A Dynamic Priority-Based Approach to Concurrent Toolpath Planning for Multi-Material Layered Manufacturing. ComputerAided Design, 42, 1095-1107. https://doi.org/10.1016/j.cad.2010.07.004

[10] Jin, Y., He, Y., Xue, G. and Fu, J. (2015) A Parallel-Based Path Generation Method for Fused Deposition Modeling. The International Journal of Advanced Manufacturing Technology, 77, 927-937. https://doi.org/10.1007/s00170-014-6530-Z

[11] Wkh, R.I., Frqvwudlqwv, P., Dgglwlyh, R.I., Surfhvvhv, P., Lwv, L.V. and Vorzhu, U. (2015) Optimizing Material Deposition Direction for Functional Internal Architecture in Additive Manufacturing Process. Procedia Manufacturing, 1, 378-392. https://doi.org/10.1016/j.promfg.2015.09.045

[12] Lynn, R., Saldana, C., Kurfess, T., Reddy, N., Simpson, T., Jablokow, K., Tucker, T., Tedia, S. and Williams, C. (2016) Toward Rapid Manufacturability Analysis Tools for Engineering Design Education. Procedia Manufacturing, 5, 1183-1196. https://doi.org/10.1016/j.promfg.2016.08.093

[13] Ponche, R., Kerbrat, O., Mognol, P. and Hascoet, J. (2014) A Novel Methodology of Design for Additive Manufacturing Applied to Additive Laser Manufacturing 
Process. Robotics and Computer-Integrated Manufacturing, 30, 389-398. https://doi.org/10.1016/j.rcim.2013.12.001

[14] Bhashyam, S., Shin, K.H. and Dutta, D. (2006) An Integrated CAD System for Design of Heterogeneous Objects. Rapid Prototyping Journal, 6, 119-135. https://doi.org/10.1108/13552540010323547

[15] Rosen, D.W. (2017) Computer-Aided Design for Additive Manufacturing of Cellular Structures Computer-Aided Design for Additive Manufacturing of Cellular Structures. Computer-Aided Design and Applications, 4360, 585-594.

[16] Domingo-Espin, M., Puigoriol-Forcada, J.M., Garcia-Granada, A.A., Llumà, J., Borros, S. and Reyes, G. (2015) Mechanical Property Characterization and Simulation of Fused Deposition Modeling Polycarbonate Parts. Materials \& Design, 83, 670-677. https://doi.org/10.1016/j.matdes.2015.06.074

[17] Alafaghani, A., Qattawi, A., Alrawi, B. and Guzman, A. (2017) Experimental Optimization of Fused Deposition Modelling Processing Parameters: A Design for Manufacturing Approach. Procedia Manufacturing.

[18] Garg, A. and Bhattacharya, A. (2016) An Insight to the Failure of FDM Parts under Tensile Loading Finite Element Analysis and Experimental Study. International Journal of Mechanical Sciences, 120, 225-236. https://doi.org/10.1016/j.ijmecsci.2016.11.032

[19] Roberson, D.A. and Siqueiros, J.G. (2016) Novel Polycarbonate/SEBS-g-MA Blend for FDM-Type 3D Printing. ANTEC, 10-14.

[20] Roberson, D.A., Shemelya, C.M., MacDonald, E. and Wicker, R.B. (2015) Expanding the Applicability of FDM-Type Technologies through Materials Development. Rapid Prototyping Journal, 21, 137-143. https://doi.org/10.1108/RPJ-12-2014-0165

[21] Masood, S.H. and Song, W.Q. (2004) Development of New Metal/Polymer Materials for Rapid Tooling Using Fused Deposition Modelling. Materials \& Design, 25, 587-594. https://doi.org/10.1016/j.matdes.2004.02.009

[22] All3DP (2017) 30 Types of 3D Printer Filament-Guide \& Amp; Comparison Chart All3DP. https://all3dp.com/best-3d-printer-filament-types-pla-abs-pet-exotic-wood-metal/

[23] Ehrig, F. (2016) Mechanical Properties of 3D Printed PLA Test Specimen. 14th International Symposium on Bioplastics, Biocomposites, and Biorefining Conference, 31 May-3 June 2016.

[24] Galantucci, L.M., Lavecchia, F. and Percoco, G. (2010) Quantitative Analysis of a Chemical Treatment to Reduce Roughness of Parts Fabricated Using Fused Deposition Modeling. CIRP Annals-Manufacturing Technology, 59, 247-250. https://doi.org/10.1016/j.cirp.2010.03.074

[25] Anderson, T.M. (2017) Anatomy of a 3D Printer: How Does a 3D Printer Work? MatterHackers. https://www.matterhackers.com/articles/anatomy-of-a-3d-printer\%0A

[26] Sun, Q., Rizvi, G.M., Bellehumeur, C.T. and Gu, P. (2008) Effect of Processing Conditions on the Bonding Quality of FDM Polymer Filaments. Rapid Prototyping Journal, 14, 72-80. https://doi.org/10.1108/13552540810862028

[27] Ultimaker.com (2017) Ultimaker 3 Specifications. https://ultimaker.com/en/products/ultimaker-3/specifications

[28] The ALL-New Makerbot Replicator. 2017. https://www.makerbot.com/replicator/

[29] BCN3D Sigma Release 2017-BCN3D Technologies. 2017. https://www.bcn3dtechnologies.com/en/3d-printer/bcn3d-sigma/\%0A 
[30] Childs, T.H.C. and Juster, N.P. (1994) Linear and Geometric Accuracies from Layer Manufacturing. CIRP Annals-Manufacturing Technology, 43, 163-166. https://doi.org/10.1016/S0007-8506(07)62187-8

[31] Johnson, W.M., Rowell, M., Deason, B. and Eubanks, M. (2011) Benchmarking Evaluation of an Open Source Fused Deposition Modeling Additive Manufacturing System. Proceedings of 22nd Annual International Solid Freeform Fabrication Symposium, 197-211.

[32] Mohamed, O.A., Masood, S.H. and Bhowmik, J.L. (2015) Optimization of Fused Deposition Modeling Process Parameters: A Review of Current Research and Future Prospects. Advances in Manufacturing, 3, 42-53. https://doi.org/10.1007/s40436-014-0097-7

[33] Belter, J.T. and Dollar, A.M. (2015) Strengthening of 3D Printed Fused Deposition Manufactured Parts Using the Fill Compositing Technique. PLoS ONE, 10, 1-19. https://doi.org/10.1371/journal.pone.0122915

[34] Kataria, A., Rosen, D.W., Kataria, A. and Rosen, D.W. (2001) Building around Inserts: Methods for Fabricating Complex Devices in Stereolithography. Rapid Prototyping Journal, 7, 253-262. https://doi.org/10.1108/13552540110410459

[35] Chen, X.A., Coros, S., Mankoff, J. and Hudson, S.E. (2015) Encore: 3D Printed Augmentation of Everyday Objects with Printed-Over, Affixed and Interlocked Attachments. Proceeding SIGGRAPH'15 ACM SIGGRAPH.

[36] Ma, R.R., Belter, J.T. and Dollar, A.M. (2015) Hybrid Deposition Manufacturing: Design Strategies for Multimaterial Mechanisms via Three-Dimensional Printing and Material Deposition. Journal of Mechanisms and Robotics, 7, Article ID: 021002. https://doi.org/10.1115/1.4029400

[37] Klahn, C., Singer, D. and Meboldt, M. (2016) Design Guidelines for Additive Manufactured Snap-Fit Joints. Procedia CIRP, 50, 264-269.

https://doi.org/10.1016/j.procir.2016.04.130

[38] Chohan, J.S. and Singh, R. (2016) Enhancing Dimensional Accuracy of FDM Based Biomedical Implant Replicas by Statistically Controlled Vapor Smoothing Process. Progress in Additive Manufacturing, 1, 105-113.

https://doi.org/10.1007/s40964-016-0009-4

[39] Kaveh, M., Badrossamay, M., Foroozmehr, E. and Hemasian Etefagh, A. (2015) Optimization of the Printing Parameters Affecting Dimensional Accuracy and Internal Cavity for HIPS Material Used in Fused Deposition Modeling Processes. Journal of Materials Processing Technology, 226, 280-286. https://doi.org/10.1016/j.jmatprotec.2015.07.012

[40] Sahu, R.K., Mahapatra, S.S. and Sood, A.K. (2013) A Study on Dimensional Accuracy of Fused Deposition Modeling (FDM) Processed Parts Using Fuzzy Logic. Journal for Manufacturing Science \& Production, 13, 183. https://doi.org/10.1515/jmsp-2013-0010

[41] Boschetto, A. and Bottini, L. (2014) Accuracy Prediction in Fused Deposition Modeling. The International Journal of Advanced Manufacturing Technology, 73, 913 928. https://doi.org/10.1007/s00170-014-5886-4

[42] Sood, A.K., Ohdar, R.K. and Mahapatra, S.S. (2009) Improving Dimensional Accuracy of Fused Deposition Modelling Processed Part Using Grey Taguchi Method. Materials \& Design, 30, 4243-4252. https://doi.org/10.1016/j.matdes.2009.04.030

[43] Manikandan, S., Kumar, A.S.S. and Sharma, C. (2015) Investigation on the Effect of Fused Deposition Modeling Process Parameters on Flexural and Surface Roughness Properties of PC-ABS Blend. International Journal on Recent Technologies in Mechanical and Electrical Engineering, 2, 41-47. 
[44] Ahn, D., Kweon, J.-H., Kwon, S., Song, J. and Lee, S. (2009) Representation of Surface Roughness in Fused Deposition Modeling. Journal of Materials Processing Technology, 209, 5593-5600. https://doi.org/10.1016/j.jmatprotec.2009.05.016

[45] Kumar, S., Kannan, V. and Sankaranarayanan, G. (2014) Parameter Optimization of ABS-M30i Parts Produced by Fused Deposition Modeling for Minimum Surface Roughness. International Journal of Current Engineering and Technology, No. 3, 93-97.

[46] McCullough, E.J. and Yadavalli, V.K. (2013) Surface Modification of Fused Deposition Modeling ABS to Enable Rapid Prototyping of Biomedical Microdevices. Journal of Materials Processing Technology, 213, 947-954. https://doi.org/10.1016/j.jmatprotec.2012.12.015

[47] Alhubail, M., Alenezi, D. and Aldousiri, B. (2013) Taguchi-Based Optimisation of Process Parameters of Fused Deposition Modelling for Improved Part Quality. International Journal of Engineering Research and Technology, 2, 2505-2519.

[48] Garg, A., Bhattacharya, A. and Batish, A. (2016) Chemical Vapor Treatment of ABS Parts Built by FDM: Analysis of Surface Finish and Mechanical Strength. The International Journal of Advanced Manufacturing Technology, 1-17.

[49] Akande, S.O. (2015) Dimensional Accuracy and Surface Finish Optimization of Fused Deposition Modelling Parts using Desirability Function Analysis. International Journal of Engineering Research and Technology, 4, 196-202.

[50] Teitelbaum, G.A., Goaer, Y. and Schmidt, L.C. (2009) Examining Potential Design Guidelines for Use in Fused Deposition Modeling to Reduce Build Time and Material Volume. ASME 2009 International Design Engineering Technical Conferences \& Computers and Information in Engineering Conference, San Diego, 1-10. https://doi.org/10.1115/detc2009-87491

[51] Ahn, S.-H., Montero, M., Odell, D., Roundy, S. and Wright, P.K. (2002) Anisotropic Material Properties of Fused Deposition Modeling ABS. Rapid Prototyping Journal, 8, 248-257. https://doi.org/10.1108/13552540210441166

[52] Lee, C.S., Kim, S.G., Kim, H.J. and Ahn, S.H. (2007) Measurement of Anisotropic Compressive Strength of Rapid Prototyping Parts. Journal of Materials Processing Technology, 187, 627-630. https://doi.org/10.1016/j.jmatprotec.2006.11.095

[53] Sood, A.K., Ohdar, R.K. and Mahapatra, S.S. (2012) Experimental Investigation and Empirical Modelling of FDM Process for Compressive Strength Improvement. Journal of Advanced Research, 3, 81-90. https://doi.org/10.1016/j.jare.2011.05.001

[54] Anitha, R., Arunachalam, S. and Radhakrishnan, P. (2001) Critical Parameters Influencing the Quality of Prototypes in Fused Deposition Modelling. Journal of Materials Processing Technology, 118, 385-388.

https://doi.org/10.1016/S0924-0136(01)00980-3

[55] Vayre, B., Vignat, F. and Villeneuve, F. (2012) Designing for Additive Manufacturing. Procedia CIRP, 3, 632-637. https://doi.org/10.1016/j.procir.2012.07.108

[56] Raut, S., Jatti, V.S., Khedkar, N.K. and Singh, T.P. (2014) Investigation of the Effect of Built Orientation on Mechanical Properties and Total Cost of FDM Parts. Procedia Materials Science, 6, 1625-1630. https://doi.org/10.1016/j.mspro.2014.07.146

[57] Chang, D.Y. and Huang, B.H. (2011) Studies on Profile Error and Extruding Aperture for the RP Parts Using the Fused Deposition Modeling Process. The International Journal of Advanced Manufacturing Technology, 53, 1027-1037. https://doi.org/10.1007/s00170-010-2882-1

[58] Ablat, M.A. and Qattawi, A. (2016) Numerical Simulation of Sheet Metal Forming: A Review. The International Journal of Advanced Manufacturing Technology, 89, 1235-1250. https://doi.org/10.1007/s00170-016-9103-5 
[59] Shojib Hossain, M., Espalin, D., Ramos, J., Perez, M. and Wicker, R. (2014) Improved Mechanical Properties of Fused Deposition Modeling-Manufactured Parts through Build Parameter Modifications. Journal of Manufacturing Science and Engineering, 136, 61002. https://doi.org/10.1115/1.4028538

[60] Tymrak, B.M., Kreiger, M. and Pearce, J.M. (2014) Mechanical Properties of Components Fabricated with Open-Source 3-D Printers under Realistic Environmental Conditions.

[61] Knoop, F. and Schoeppner, V. (2015) Mechanical and Thermal Properties of Fdm Parts Manufactured with Polyamide 12. Solid Freeform Fabrication Symposium, Austin, 10 August 2015, 935-948.

[62] Klahn, C., Leutenecker, B. and Meboldt, M. (2014) Design for Additive Manufacturing-Supporting the Substitution of Components in Series Products. Procedia CIRP, 21, 138-143. https://doi.org/10.1016/j.procir.2014.03.145

[63] Salonitis, K. and Al Zarban, S. (2015) Redesign Optimization for Manufacturing Using Additive Layer Techniques. Procedia CIRP, 36, 193-198. https://doi.org/10.1016/j.procir.2015.01.058

[64] Hallgren, S., Pejryd, L. and Ekengren, J. (2016) (Re) Design for Additive Manufacturing. Procedia CIRP, 50, 246-251. https://doi.org/10.1016/j.procir.2016.04.150

Scientific Research Publishing

Submit or recommend next manuscript to SCIRP and we will provide best service for you:

Accepting pre-submission inquiries through Email, Facebook, LinkedIn, Twitter, etc. A wide selection of journals (inclusive of 9 subjects, more than 200 journals)

Providing 24-hour high-quality service

User-friendly online submission system

Fair and swift peer-review system

Efficient typesetting and proofreading procedure

Display of the result of downloads and visits, as well as the number of cited articles

Maximum dissemination of your research work

Submit your manuscript at: http://papersubmission.scirp.org/

Or contact ojapps@scirp.org 